\title{
Management strategies in the treatment of neonatal and pediatric gastroenteritis
}

This article was published in the following Dove Press journal:

Infection and Drug Resistance

22 October 2013

Number of times this article has been viewed

\author{
Simona Ciccarelli \\ Ilaria Stolfi' \\ Giuseppe Caramia² \\ 'Neonatal Intensive Care Unit, \\ Sapienza University of Rome, Rome, \\ Italy; ${ }^{2}$ Division of Neonatology \\ and Pediatrics, Maternal and Child \\ Hospital "G. Salesi”, Ancona, Italy
}

\begin{abstract}
Acute gastroenteritis, characterized by the onset of diarrhea with or without vomiting, continues to be a major cause of morbidity and mortality in children in mostly resourceconstrained nations. Although generally a mild and self-limiting disease, gastroenteritis is one of the most common causes of hospitalization and is associated with a substantial disease burden. Worldwide, up to $40 \%$ of children aged less than 5 years with diarrhea are hospitalized with rotavirus. Also, some microorganisms have been found predominantly in resource-constrained nations, including Shigella spp, Vibrio cholerae, and the protozoan infections. Prevention remains essential, and the rotavirus vaccines have demonstrated good safety and efficacy profiles in large clinical trials. Because dehydration is the major complication associated with gastroenteritis, appropriate fluid management (oral or intravenous) is an effective and safe strategy for rehydration. Continuation of breastfeeding is strongly recommended. New treatments such as antiemetics (ondansetron), some antidiarrheal agents (racecadotril), and chemotherapeutic agents are often proposed, but not yet universally recommended. Probiotics, also known as "food supplement," seem to improve intestinal microbial balance, reducing the duration and the severity of acute infectious diarrhea. The European Society for Paediatric Gastroenterology, Hepatology and Nutrition and the European Society of Paediatric Infectious Diseases guidelines make a stronger recommendation for the use of probiotics for the management of acute gastroenteritis, particularly those with documented efficacy such as Lactobacillus rhamnosus GG, Lactobacillus reuteri, and Saccharomyces boulardii. To date, the management of acute gastroenteritis has been based on the option of "doing the least": oral rehydration-solution administration, early refeeding, no testing, no unnecessary drugs.
\end{abstract}

Keywords: acute infective gastroenteritis, diarrhea, oral rehydration solution, children, vomiting, probiotics

\section{Introduction and epidemiology}

Acute gastroenteritis (AGE), characterized by the onset of diarrhea with or without vomiting, continues to be a major cause of morbidity and mortality in children mostly in resource-constrained nations. Although generally it is a mild and self-limiting disease, gastroenteritis is one of the most common causes of hospitalization and is associated with a substantial disease burden., ${ }^{1,2}$ According to the World Health Organization (WHO), diarrhea is defined as the passage of three or more loose or liquid stools per day, or more frequently than is normal for the individual. ${ }^{3}$ When young children suddenly experience an episode of acute diarrhea, with or without vomiting, infectious gastroenteritis is by far the most common explanation. ${ }^{4}$ Viewed from a global perspective, gastroenteritis in children is of enormous public health importance. 
Worldwide, about 10.6 million children still die every year before reaching their fifth birthday. Gastroenteritis alone is responsible for almost $20 \%$ of the deaths. ${ }^{4}$

In spite of the intense promotion of oral rehydration solution (ORS) at the community level and the training of health care workers, diarrhea mortality remains unacceptably high: more than 2 million children aged less than 5 years die each year from gastroenteritis, almost all living in resource-constrained nations, where acute diarrhea represents a leading cause of child mortality, second only to pneumonia. ${ }^{2}$ AGE causes 1.5 million visits to primary care providers each year and 220,000 hospital admissions for children under the age of 5 years; that is $10 \%$ of all the hospital admissions of children in the US. ${ }^{5}$ In general, resource-constrained nations have a higher rate of hospital admissions compared to rich nations. ${ }^{6}$ In the US, the admission rate is nine per 1000 , per year, for children younger than 5 years old. ${ }^{5}$ In England each year, 9.4 million cases of gastroenteritis occur in the community and 1.5 million present to their primary care doctor. ${ }^{4}$ In Europe, rotavirus infection accounts for more than $50 \%$ of hospitalizations for gastroenteritis and about one-third of emergency department visits. ${ }^{2,6,7}$ Not surprisingly, the economic burden of acute diarrhea is substantial, not only in management costs but also in indirect costs, such as absence from work by parents or caregivers of sick children. ${ }^{2}$ The severity of acute diarrhea is related to etiology, with rotavirus infection disproportionately implicated in severe cases that frequently require hospitalization. ${ }^{2,8}$ Worldwide, up to $40 \%$ of children aged less than 5 years with diarrhea are hospitalized with rotavirus: while most of the episodes are mild, about $10 \%$ of cases lead to dehydration requiring a doctor visit, and in resource-constrained nations, one in 250 children will die from this dehydration. ${ }^{7-11}$ In Europe, rotavirus infection accounts for more than $50 \%$ of hospitalizations for gastroenteritis and about one-third of emergency department visits. ${ }^{2,7}$ Otherwise, some agents have been found predominantly in resource-constrained nations, including Shigella spp, Vibrio cholerae, and the protozoan infections. Mode of transmission is mainly horizontal, through physical contact with an infected person or with their excretions. The pathogens, most frequently transmitted during the passage through the birth canal, are enteropathogenic Escherichia coli, Salmonella, and enterovirus. Although rare, the passage of the germ can also occur transplacentally during bacteremia. Several maternal infections are asymptomatic. Horizontal transmission can occur through direct contact with siblings, parents, or health care workers. Some cases of transmission through the ingestion of contaminated water or infant formula are also reported. Some viral infectious agents, such as adenovirus and rotavirus, can be transmitted by air. ${ }^{12}$

The relatively low incidence of the disease in newborns is the result of several factors: breastfeeding and the universal practice of giving birth at home in rural villages, and improvements in social and educational standards and medical care in advanced countries. ${ }^{13,14}$ Otherwise, newborns are particularly susceptible to enteric infections in early life, due to reduced local and systemic immune response, absence of an adequate intestinal flora, and reduced gastric acidity. In the newborn, the protective role of gastric motility and of the intestinal mucus is still uncertain. Other external factors contribute to the balance of the intestinal ecosystem: nutrition, type of delivery, hygiene habits, use of antibiotics in the mother and infant and the supplementation with probiotics and/or prebiotic oligosaccharides in the newborn. ${ }^{15-17}$ The mortality risk for very low-birth-weight infants (less than $1500 \mathrm{~g}$ ) due to acute diarrhea is 100 times higher than for infants of low or appropriate birth weight (more than $1500 \mathrm{~g}$ ). Acute diarrhea has several risks and complications; it may lead to lifethreatening dehydration and electrolyte disturbances. When diarrhea is not halted, there is a risk of disturbed digestion and absorption of nutrients with nutritional deterioration. ${ }^{13}$ Prevention is essential, and all health professionals should ensure caregiver education in the following main principles of prevention: ${ }^{13}$

- Full and exclusive breastfeeding that protects against intestinal infections and prevents exposure to environmental contamination. ${ }^{18,19}$ Thriving breastfed babies under 6 months of age do not require water supplements, even in hot weather. ${ }^{19,20}$

- Provision of safe water for drinking and food preparation.

- Proper hand-washing hygiene after toilet use and before food preparation and feeding.

- Safe disposal of human and other waste.

\section{Etiology}

Table $1 \mathrm{~A}-\mathrm{C}$ shows the main characteristics of the principal bacterial, viral, fungal, and parasitic enteropathogens, respectively: typical age of presentation, type of diarrhea, duration of symptoms, clinical features, transmission, and seasonality.

\section{Bacterial enteritis (Table IA)}

Some bacteria directly invade the intestinal mucosa, causing an inflammatory response of the host, while others cause damage by producing toxins. This classification is 
not always well defined, because some agents use both these pathogenetic strategies to induce disease. In Europe, the most common bacterial agent is either Salmonella or Campylobacter, depending on country. ${ }^{6}$

Aeromonas hydrophila and Plesiomonas shigelloides (previously also known as Aeromonas shigelloides) belonging to the family of Vibronacee, can cause watery diarrhea. The pathogenic role of $A$. hydrophila as an enteric pathogen causing gastroenteritis is difficult to confirm, because of the frequency of other pathogens isolated with A. hydrophila in symptomatic and asymptomatic subjects. But $A$. hydrophila is recognized increasingly as a clinically significant enteric pathogen associated with diarrhea also in children younger than 2 years of age living in a rural community, and is linked to local drinking water sources. ${ }^{21}$

Campylobacter is the most common enteropathogen after 5 years of age, particularly in Northern European countries. ${ }^{6}$ C. jejuni and C. coli infections are endemic worldwide and hyperendemic in resource-constrained nations. Infants and young adults are most often infected. ${ }^{22} C$. jejuni, followed by C. coli and C. lari, are the most common bacterial causes of acute diarrheal illnesses in rich nations. ${ }^{22} C$. jejuni has invasive properties, leading to epithelial ulceration and inflammatory infiltrates in the lamina propria, mainly in the colon, ileum, and jejunum. Some $C$. jejuni isolates elaborate very low levels of cytotoxins, similar to Shiga toxin. Some isolates have been reported to elaborate an enterotoxin similar to cholera toxin. Enterotoxin production has been more frequently observed in isolates from resource-constrained nations, where infection by $C$. jejuni has been associated with watery diarrhea. However, the clinical significance of the toxigenicity of these organisms is still unclear. ${ }^{23}$ Symptoms and signs of $C$. enteritis are not distinctive enough to differentiate it from illness caused by many other enteric pathogens. Diarrhea is often associated with blood, but it can be difficult to distinguish from other invasive forms. A cholera-like illness with massive watery diarrhea may also occur. Bacteremia is uncommon (less than 1\%) in immunocompetent patients with C. jejuni infection. ${ }^{22}$ Newborn infection by Campylobacter spp is rare; most cases were born to mothers with Campylobacter diarrhea at the time of delivery. The transplacental passage of Campylobacter fetus is responsible for abortion, premature birth, bacteremia, and meningitis.

C. jejuni/coli infections can cause a series of complications as reactive arthritis, irritable bowel syndrome, and Guillain-Barré Syndrome (GBS), an acute neurologic disease driven by autoimmunity and molecular mimicry in which the body stages a cell-mediated and humoral immunological response against peripheral nerve myelin. A recent systematic review of GBS estimated that $40 \%-70 \%$ of all cases are preceded by an acute infectious illness, of which $22 \%-53 \%$ are upper respiratory infections and 6\%-26\% are gastrointestinal infections, one of the most common being enteritis due to Campylobacter. ${ }^{24,25}$ Several studies have shown that patients with GBS (most of cases associated with the variant acute motor axonal neuropathy) have a recent history of infection due to $C$. jejuni. ${ }^{26}$

Clostridium difficile is a major nosocomial pathogen that causes a spectrum of intestinal disease from uncomplicated antibiotic-associated diarrhea to severe, possibly fatal, antibiotic-associated colitis. ${ }^{27}$ In the last 5-7 years, a change in the epidemiologic pattern of $C$. difficile infection characterized by an increasing incidence and severity of infection has been observed. A few epidemiological studies recently conducted in the pediatric population demonstrated a twofold increase in the incidence of $C$. difficile infection in the last 5 years, but with no increase in the incidence of severe complications, such as the need for colectomy or mortality. ${ }^{28,29}$ The clinical presentation of $C$. difficile-associated disease can range from asymptomatic carriage in the gastrointestinal tract and mild diarrhea to potentially fatal pseudomembranous colitis. ${ }^{30}$ Diarrhea is watery and usually nonbloody, but approximately $5 \%-10 \%$ of patients have bloody diarrhea. Fecal material typically contains excess mucus, and pus or blood may also be noted. ${ }^{31}$ The disease may progress to a pseudomembranous colitis, possibly including intestinal perforation and toxic megacolon. Neonatal infections by C. difficile can be asymptomatic, but usually display fever, diarrhea, and irritability within 48 hours after production of the toxins. ${ }^{32}$

Escherichia coli are the predominant nonpathogenic facultative anaerobe of human colonic flora and usually remain harmlessly confined to the intestinal lumen. Some $E$. coli have evolved the ability to cause a broad spectrum of human diseases, and different types associated with enteric infections are classified into five groups according to their virulence properties and are briefly described here.

Enteroaggregative E. coli (EAEC) serotypes exhibit a characteristic aggregative pattern of adherence and produce persistent gastroenteritis and diarrhea in infants and children in resource-constrained nations. ${ }^{22}$ Enteroinvasive E. coli serotypes have properties similar to invasive Salmonella, but the presence of blood in the stool is less frequent. These can also produce an enterotoxin that cause watery diarrhea, resembling the effects of Shigella in children and adults. Enteropathogenic E. coli (EPEC) serotypes in the past were 


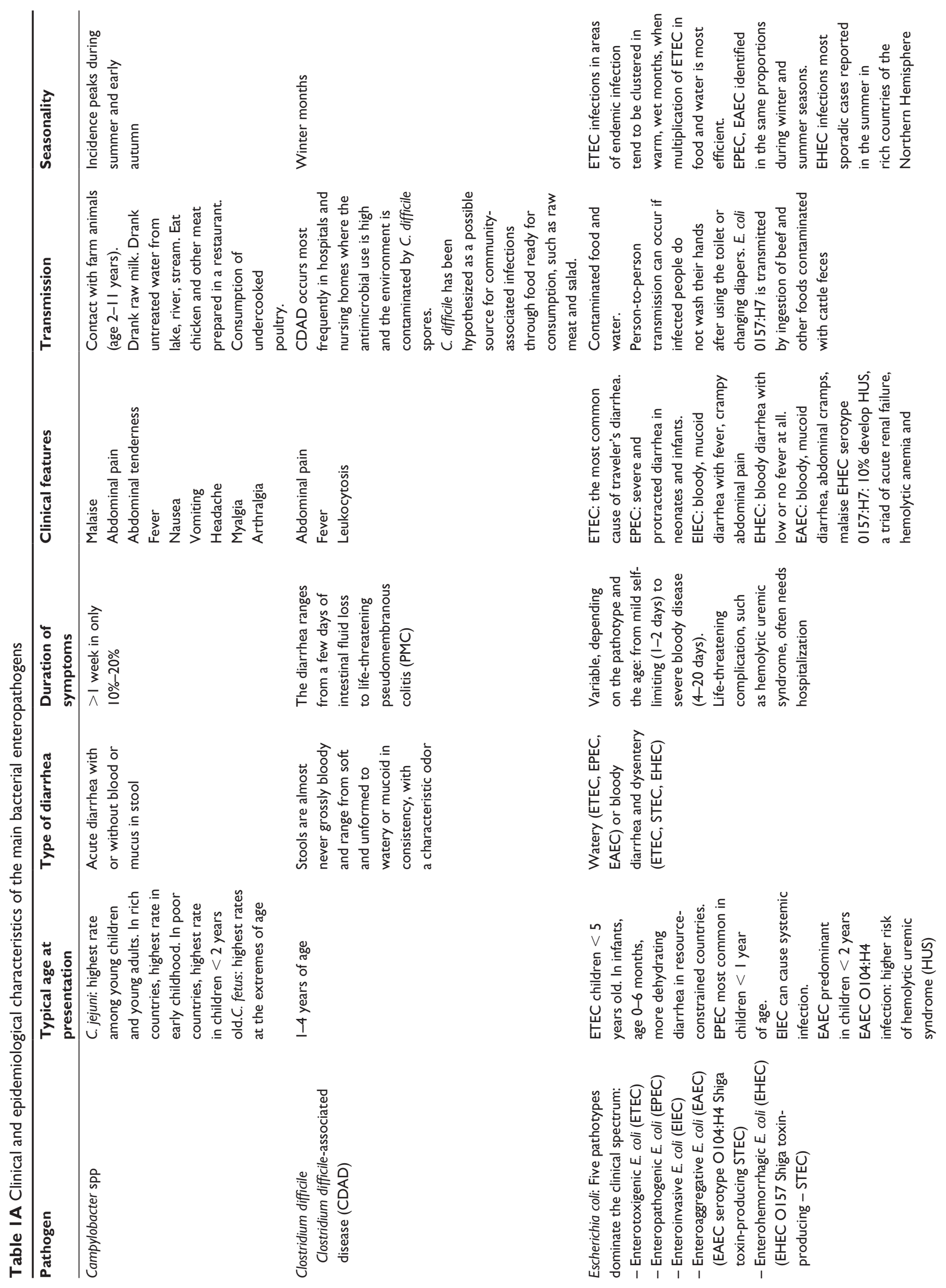



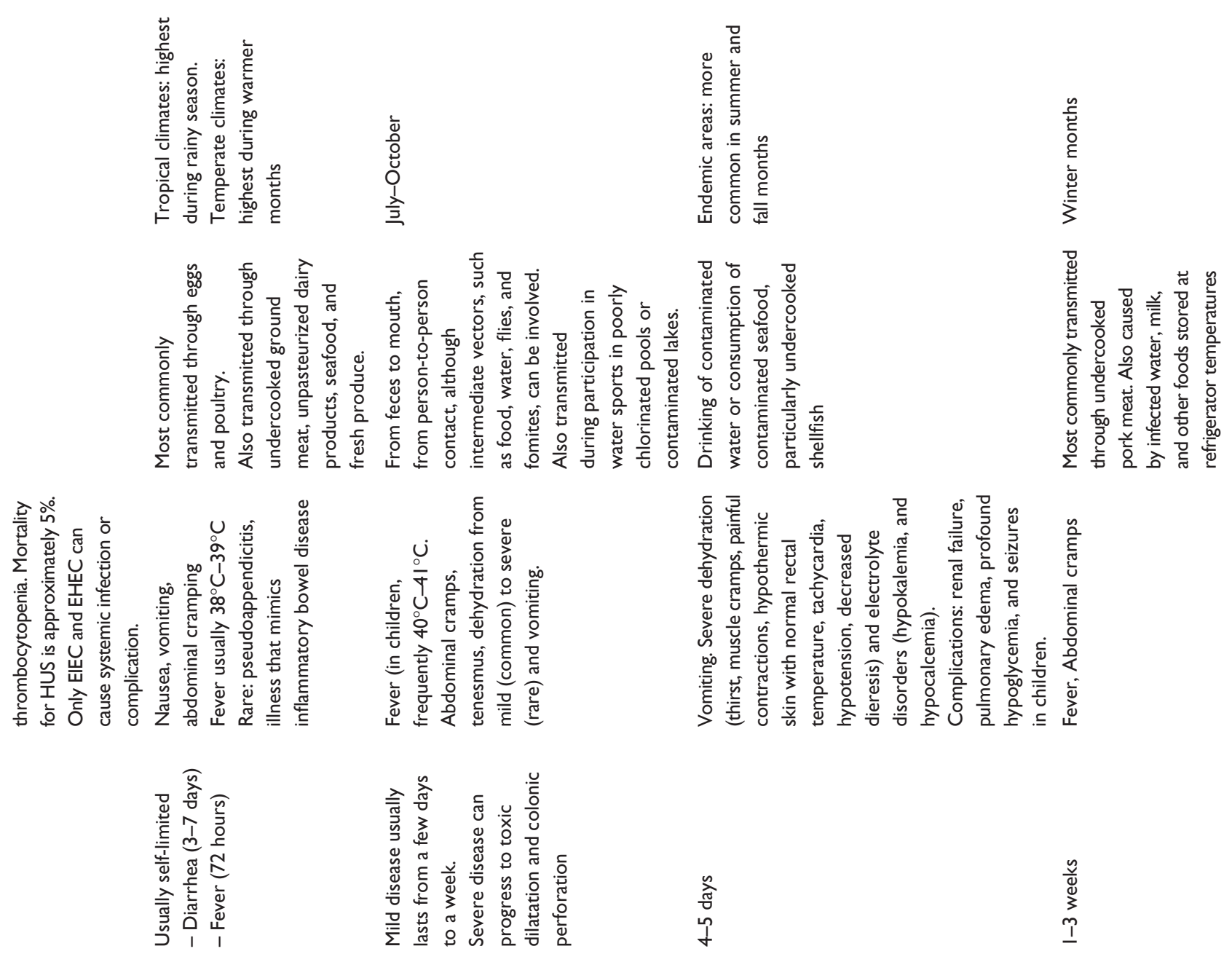

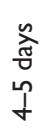

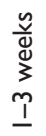
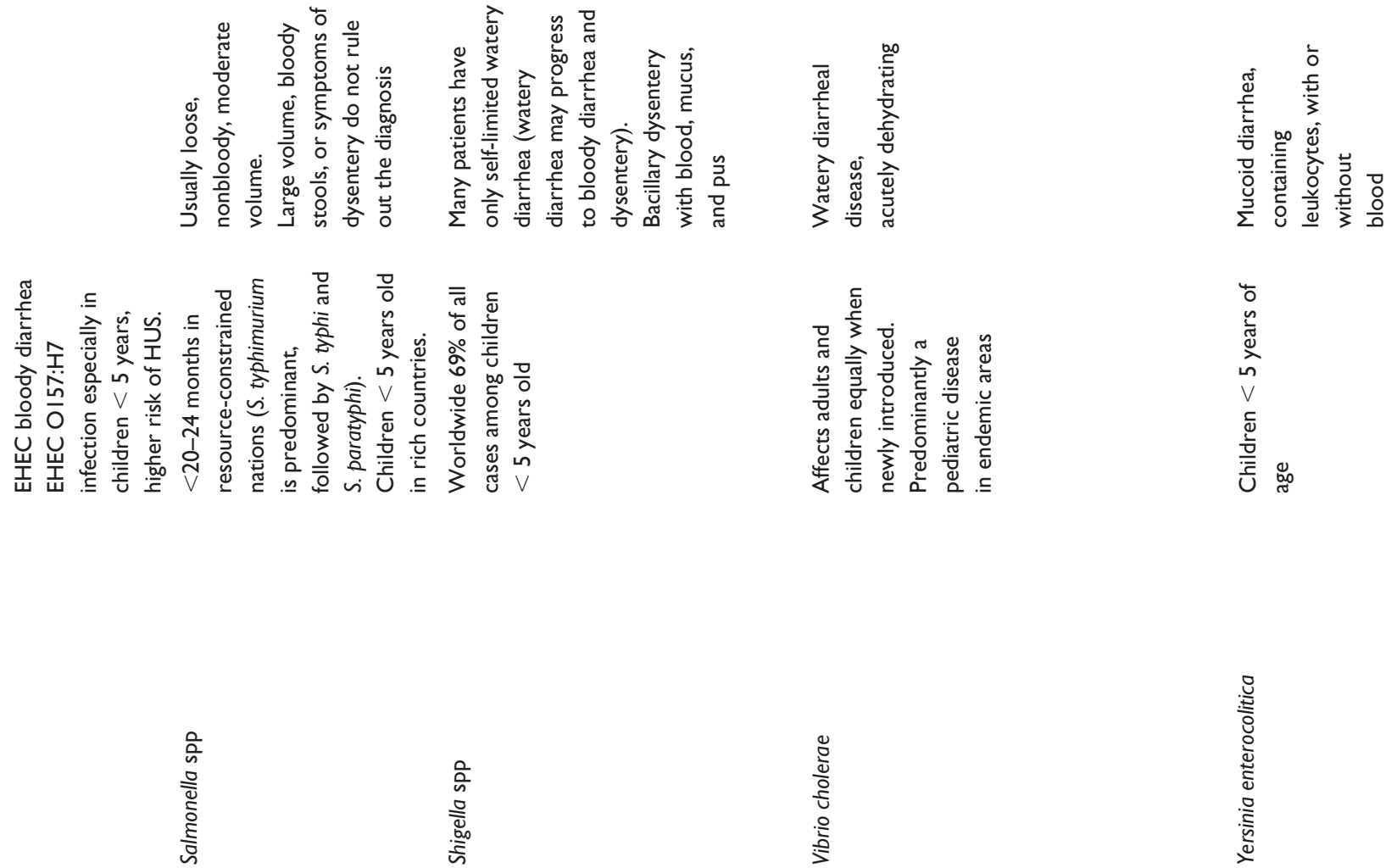

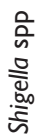

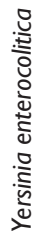




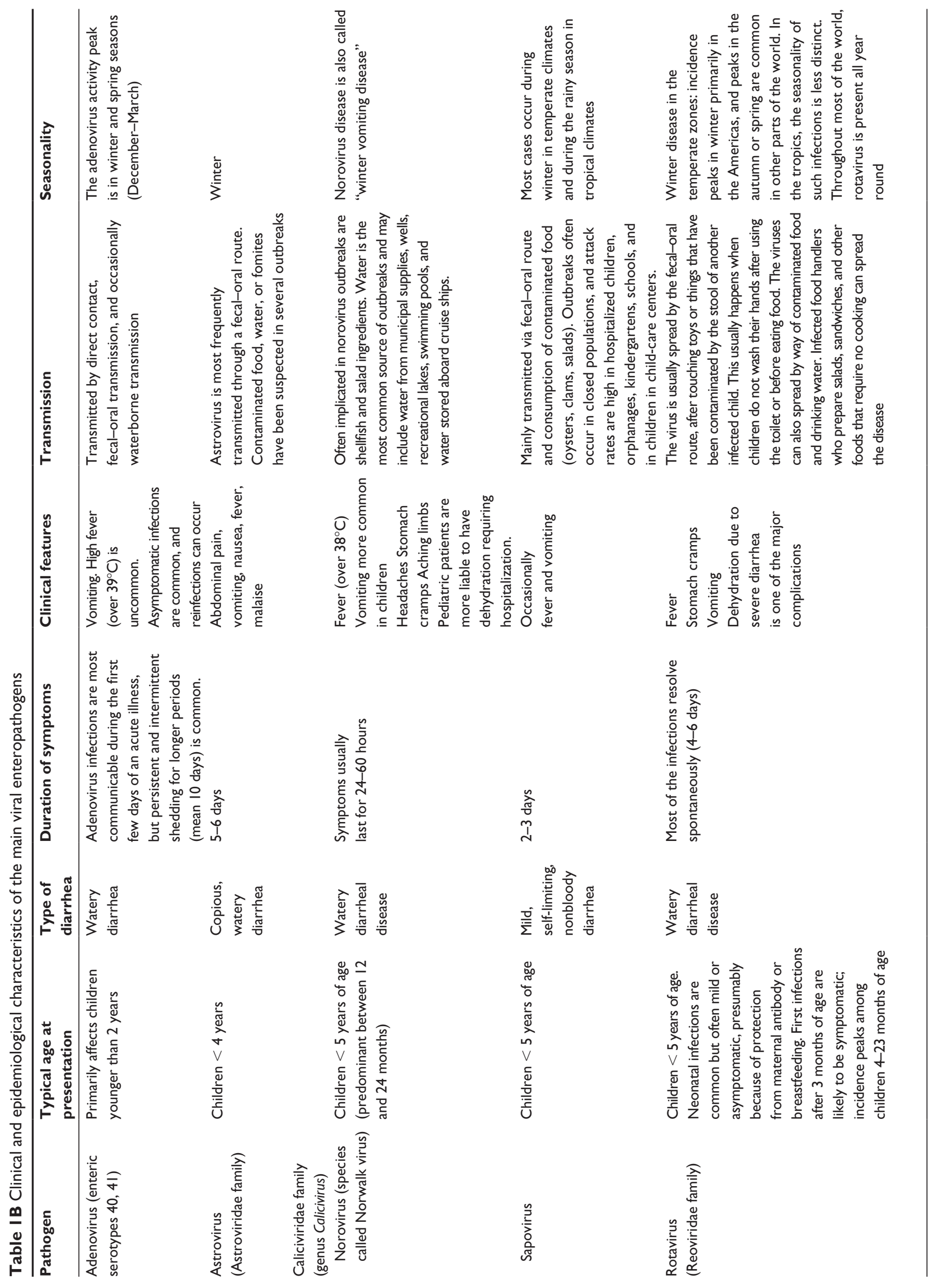


associated with serious outbreaks of diarrhea in newborn nurseries in the US. They remain an important cause of acute infantile diarrhea in resource-constrained nations. Disease is rare in adults. Enterotoxigenic E. coli (ETEC) serotypes are a major cause of traveler's diarrhea and diarrhea in children in resource-constrained nations. The main hallmarks of this type of bacteria are expression of one or more enterotoxins, heat-labile enterotoxin, and heat-stable enterotoxin, and presence of fimbriae used for attachment to host intestinal cells. Enterohemorrhagic E. coli (EHEC) serotypes are one of the main causes of food-borne diseases. ${ }^{33}$ Serotypes number about 50, and in rich countries are primarily responsible for gastroenteritis with bloody diarrhea, severe abdominal pain, and cramps that resolve in a few days with an adequate oral rehydration.

Since 1982, gastroenteritis from Shiga toxin-producing E. coli (STEC), an E. coli strain with the capacity to produce a cytotoxin similar to that produced by Shigella spp, has been identified as a significant health problem in the developed world. ${ }^{34,35}$ Infections with STEC, of which EHEC O157 is the most well-known serotype, have been recorded in many regions, including North America, Western Europe, Central and South America, the Middle and Far East, Africa and Australia; also, EAEC serotype O104:H4 can produce Shiga toxins (STEC). ${ }^{36-38}$ Infections by STEC are characterized by abdominal cramps and acute bloody diarrhea; ${ }^{39}$ however, more serious sequelae may also result, including hemolytic uremic syndrome (HUS), thrombocytopenia, and associated complications, which can lead to kidney failure and death in some individuals. ${ }^{36,40}$

Most outbreaks and sporadic cases of bloody diarrhea and HUS have been attributed to strains of STEC serotype O157:H7. However, in Europe and recently in the US, the role of non-O157 STEC strains (eg, O26:H11/H-, O91:H21/H-, O103:H2, O104:H4, O111:H-, O111:NM, O113:H21, O121:H19, O128:H2/H-, and O145:H28/H-) as causes of HUS, bloody diarrhea, and other gastrointestinal illnesses is being increasingly recognized..$^{33,41}$

In many studies, a significant association between illness and the consumption of pink or undercooked hamburgers, pinkish ground beef, undercooked meat, or barbecued food has been demonstrated..$^{38,41,42}$ The natural reservoirs of STEC are ruminant animals, especially cattle, and transmission to humans usually occurs via contaminated food or water.

Helicobacter pylori (previously named Campylobacter pyloridis)-infected children may have no symptoms or a wide variety of symptoms, and rarely potentially life-threatening complications, such as gastroduodenal ulcers and bleeding.
Symptoms of ulcers may include pain or discomfort (usually in the upper abdomen), bloating, an early sense of fullness with eating, lack of appetite, nausea, vomiting, blood in the stools, and diarrhea. In the last 10 years, various studies have been performed investigating its role to modify the susceptibility to gastroenteritis in children. ${ }^{43}$

A study reported an increased risk of chronic diarrhea, compared with healthy control subjects, among infected age-matched Gambian children with malnutrition. ${ }^{44}$ In a nested case-control design, the authors found an increased risk of severe cholera among $H$. pylori-infected subjects without vibriocidal antibodies. ${ }^{45}$ Similarly, in an urban slum, H. pylori infection was twice as common among subjects with typhoid fever (Salmonella typhi) ${ }^{46}$ than in neighborhood control subjects. Another study reported increased diarrhea episodes among Peruvian infants with recent H. pylori seroconversion. ${ }^{47}$ Conversely, in a Thai orphanage, no association was found between seroconversion and diarrheal disease. ${ }^{48}$ Some investigators have even speculated that local inflammatory factors induced by infection may be protective. ${ }^{49}$ In a cross-sectional study of elementary school-age children in Germany, the infection seemed associated with a reduced frequency of diarrheal illnesses. ${ }^{50}$ These epidemiological discrepancies could be explained, because $H$. pylori could be argued to increase or decrease susceptibility to enteric pathogens. Depending on the age at acquisition and the anatomical site of colonization, for example, $H$. pylori decreases gastric acid secretion in some people, thereby potentially reducing the effectiveness of the gastric acid barrier to intestinal pathogens, but increases gastric acid secretion in others. ${ }^{51}$ In this prospective study, H. pylori did not seem to increase the risk of gastroenteritis in people more than 2 years old. ${ }^{43}$ These data have recently been confirmed. ${ }^{52}$

Klebsiella, Enterobacter, Citrobacter, and Streptococcus group D have been isolated from feces of sick newborns and associated with intestinal disease, but there is insufficient evidence to define the pathogenic role of these agents.

Proteus and Providencia, although rarely, may be responsible for intestinal infections in newborns. Providencia species occur in normal feces and have been isolated from epidemic and sporadic causes of diarrhea, though their importance in the causation of diarrheal disease is not easy to assess. ${ }^{53}$

Pseudomonas aeruginosa can colonize (0\%-10\%) the intestine of the newborn during the first days of life. ${ }^{54}$ Clinically, the infection may be asymptomatic at first, later developing into grayish-blue stool color or watery diarrhea, profuse vomiting, and systemic symptoms. ${ }^{22}$ 


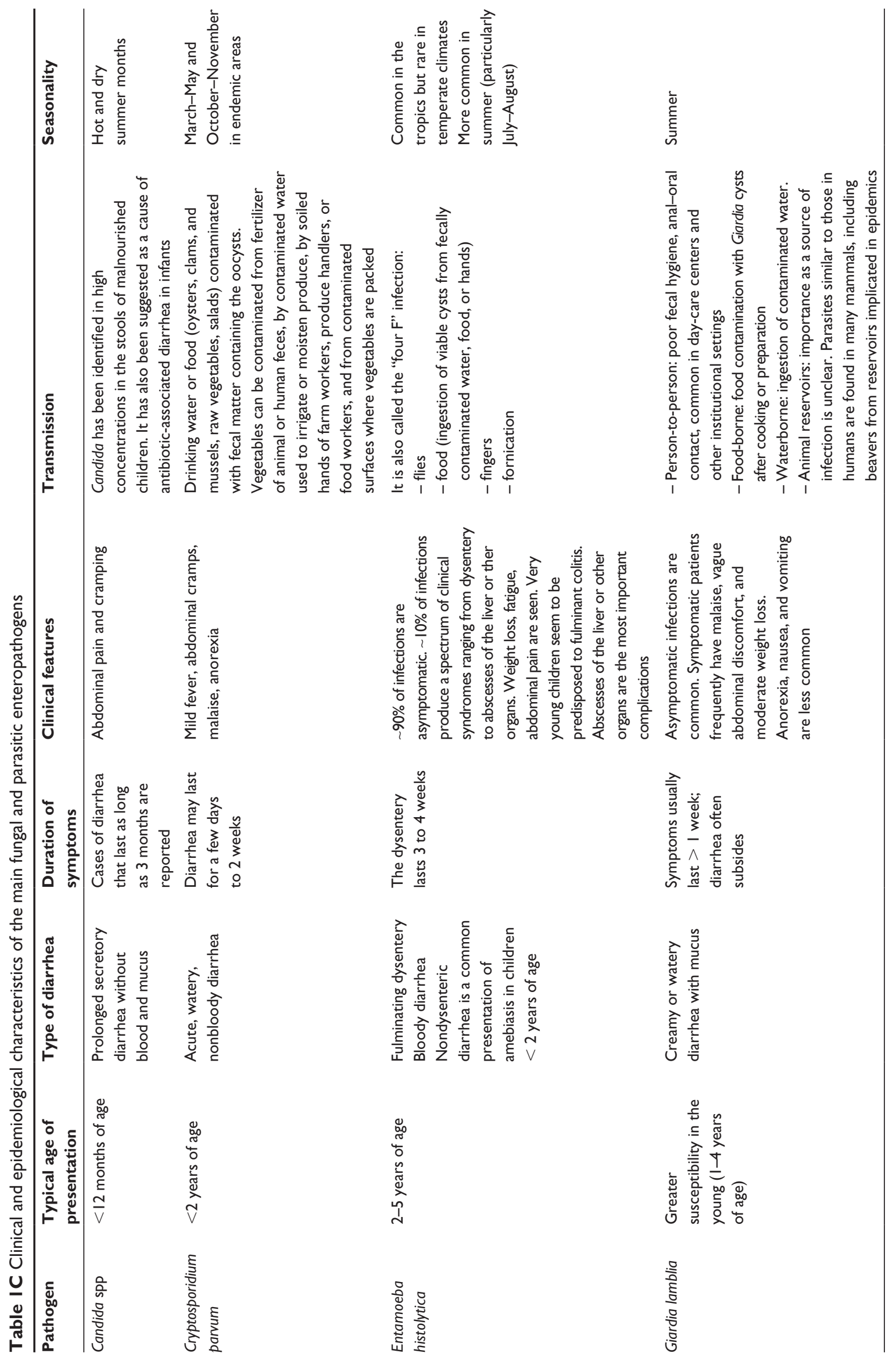


Salmonella pass through the intestinal mucosa and multiply within the lamina propria, may invade mesenteric lymphonodes, and systemic spread of the organisms can occur, giving rise to enteric fever. ${ }^{55}$ In fact, $3 \%-5 \%$ of infants may have extraintestinal symptoms. The colonization and initial invasion probably occur at the distal ileum, while the mucosal edema and cryptic abscesses are frequently in the colon. The diarrhea is due to secretion of fluid and electrolytes by the small and large intestines. The incubation period is usually 12-48 hours, rarely for a few days. ${ }^{22}$ neonatal infection by Salmonella spp is normally acquired through the birth canal, and the mother can be an asymptomatic carrier. ${ }^{55}$

Shigella spp are the leading bacterial causes of diarrhea worldwide and are relatively common in children. They cause invasive gastroenteritis, and symptoms can take as long as a week to show up, but most often begin 2-4 days after ingestion. Mild symptoms are self-limiting, but $S$. dysenteriae serotype 1 resistance to multiple antibiotics has the ability to elaborate the potent Shiga toxin, which may lead to extraintestinal complications, including HUS and death. ${ }^{56}$

Cases of neonatal infections from Staphylococcus aureus are reported in the literature. The pathogen produces two enterotoxins, G and I, that cause atrophy of intestinal villi, diarrhea, and poor growth during the first weeks of life.

Vibrio cholerae causes watery diarrhea through the production of cholera toxin without invading the intestinal mucosa.

Yersinia enterocolitica is a common enteropathogen usually causing relatively mild disease. Y. enterocolitica crosses the intestinal mucosa, replicates in Peyer's patches, and children infected present acute diarrhea associated with fever and pharyngitis, chronic or recurrent diarrhea, or abdominal pain associated with mesenteric adenitis. This infection looks like Salmonella infections, with feces containing mucus with or without blood. The pathogen, within phagocytes, can reach other sites through the bloodstream. Some of the $Y$. enterocolitica pathogenic biotypes express the yst gene encoding for an heat-stable enterotoxin that may contribute to the pathogenesis of diarrhea..$^{57,58}$

\section{Viral enteritis (Table IB)}

Viruses are responsible for approximately $70 \%$ of the episodes of acute gastroenteritis in children. Viral gastroenteritis is of shorter duration than bacterial gastroenteritis and associated with an increased risk of vomiting and dehydration compared with those without viral infection. The severity of dehydration is significantly higher in children infected with either astrovirus or rotavirus group A. Prolonged hospitalization is also more likely to occur with rotavirus infection. ${ }^{4,22,55,59,60}$

Enteric adenoviruses are a common cause of viral gastroenteritis in infants and young children. Although there are many serotypes of adenovirus that can be found in the stool especially during and after typical infections of the upper respiratory tract, only serotypes 40 and 41 cause gastroenteritis and are very difficult to grow in tissue culture. ${ }^{61}$ Adenovirus directly infects intestinal enterocytes, causing villous hypoplasia and crypt hypertrophy. The virus causes a massive infiltration of the lamina propria of the villi by mononuclear cells. Enteric adenovirus is associated with longer lasting diarrhoea, compared to other viral gents. ${ }^{4,22,55}$ Maternal antibodies are certainly protective; however, among premature and/or low-birth-weight infants the infection spreads rapidly and can be associated with a poor prognosis and high morbidity. ${ }^{5}$

Cytomegalovirus and herpes virus (CMV or HH5 and HHV6-7; family Herpesviridae, subfamily Betaherpesviridae) can cause gastrointestinal symptoms such as diarrhea or colitis with profuse hematochezia and bowel perforation. $^{62}$

Most people who are infected with a non-polio enterovirus (EV; family Picornaviridae, genus Enterovirus) have no disease, but all EV may cause diarrhea ${ }^{63}$ Human EV 68 (EV-D68) is a historically rarely reported virus linked with respiratory disease. In the last 3 years, a large increase in respiratory disease associated with EV-D68 has been reported, with documented outbreaks in North America, Europe, and Asia. ${ }^{64}$ EV71 infections can be asymptomatic or can cause diarrhea, rashes, and hand, foot, and mouth disease. However, EV71 may be responsible for severe complications, including meningitis, encephalitis, cardiovascular and respiratory problems as pulmonary edema, or heart failure. Cases of fatal EV71 encephalitis have occurred during outbreaks. Most EV71 infections occur under 3 years of age.

Coxsackie (family Picornaviridae, genus Enterovirus)A16 and EV71 are two of the major pathogens responsible for hand, foot, and mouth disease, but the most severe cases are associated with EV71. ${ }^{65,66}$

Pleconaril, a viral agent active against enteroviruses, has demonstrated efficacy against neonatal infection with systemic symptoms. However, further confirmatory studies are needed. ${ }^{67}$ Results of Phase I clinical trials suggest an EV71 vaccine has a clinically acceptable safety profile and immunogenicity. Outbreaks of EV71 are a serious socioeconomic burden not only in the Western Pacific region. For this reason, an EV71 vaccine is now being tested and seems to 
have an acceptable safety profile and clinically acceptable immunogenicity. ${ }^{68}$

Human astrovirus (family Astroviridae, genus Mamastrovirus) may also be responsible for sporadic infections or epidemics, occasionally in newborns and children. ${ }^{61,63}$

Human bocavirus (family Parvoviridae, genus Bocavirus), recently discovered, has been suggested to be involved in a large spectrum of clinical manifestations, including gastroenteritis. ${ }^{63,69}$

Human coronaviruses (HCoVs; family Coronaviridae, genus Coronavirus) are common causes of upper respiratory tract infections. A new coronavirus was found to be a causative agent of severe acute respiratory syndrome (SARS). SARS$\mathrm{HCoV}$ caused a serious lower respiratory tract infection with high mortality. Diarrhea is common in this condition, and in one study was registered in $38.4 \%$ of patients. In the same study, SARS-HCoV was also isolated from intestinal tissue, and viral RNA was detected in stool samples. Moreover, nonSARS HCoVs can be found in stool samples of children with AGE. However, most of the $\mathrm{HCoV}$ findings were coinfections with well-known enteric pathogens - norovirus and rotavirus. It is also difficult to determine whether $\mathrm{HCoVs}$ in the respiratory tract in cases of AGE were primarily causing the respiratory or gastrointestinal symptoms. $\mathrm{HCoVs}$ may also be found in occasional stool samples of children without gastroenteritis. These findings suggest that known $\mathrm{HCoVs}$ may at most have a minor etiologic role in AGE of children. ${ }^{70}$

Human rotavirus (family Reoviridae, genus Rotavirus) in the past was considered to be responsible for the most severe episodes of diarrhea in children. ${ }^{71,72}$ There have been reports of epidemics in neonatal intensive care units caused by rotavirus or enterovirus that can determine cases of necrotizing enterocolitis or necrotizing enterocolitis-like symptoms: abdominal distention, bloody diarrhea, and septicemia secondary to enteric bacteria.

Improved diagnostic tools for norovirus (family Caliciviridae, genus Norovirus): have shown that it has a major role in both epidemic and sporadic cases of gastroenteritis. ${ }^{59,73}$

Sapoviruses (family Caliciviridae, genus Sapovirus): mainly infect children younger than 5 years of age. ${ }^{59}$ The illness is milder than that caused by noroviruses. ${ }^{73}$ Antibody prevalence studies show that virtually all children are infected with sapoviruses by the time they are 5 years of age, indicating that sapovirus infection is widespread, although the illness most likely is sporadic with a high rate of asymptomatic infection. . $^{59,74,75}$

Torque teno midi virus/small anellovirus (TTMDV/SAV) is a member of the family Anelloviridae. Although human
TTV infection is ubiquitous and several infecting genogroups of the virus have been identified, to date there is no consistent evidence of a link between TTV infection of humans and specific disease. ${ }^{76-79}$ In a recent Hungarian study, viral shedding, molecular epidemiology, and genetic diversity of TTMDV/ SAV were studied in human body fluids (nasopharyngeal aspirates of children with acute respiratory diseases and serum, stool and urine samples collected from eight healthy children with previous TTMDV/SAV infection). In this study, shedding of TTMDV/SAV and related viruses was detected in two other human body fluids, feces and urine, suggesting the existence of fecal-oral/urinary-oral transmission routes beyond the originally presumed blood-borne and later-suggested respiratory route. This finding extends the number of possible successful transmission routes.

\section{Fungal enteritis (Table IC)}

The pathogenic role of Candida in neonatal diarrhea is still difficult to prove. Symptoms ascribed to Candida-associated diarrhea in the literature include prolonged secretory diarrhea with abdominal pain and cramping but without blood, mucus, fever, nausea, or vomiting. ${ }^{80}$ Disseminated Candida infection can cause intestinal symptoms similar to necrotizing enterocolitis, especially in premature infants and in infants treated with antibiotics (especially third-generation cephalosporins) and with central venous catheters or in surgical patients. ${ }^{81,82}$ Candida infections frequently develop into systemic forms, and are a major cause of morbidity and mortality in neonatal intensive care units. ${ }^{83}$ The incidence of candidemia in the neonatal intensive care unit is steadily increasing, with an estimated incidence of $1 \%-2 \%$ in very low-birth-weight infants and of 2\%-23\% in extremely low-birth-weight infants. ${ }^{84}$ Infection-associated mortality following Candida bloodstream infections is as high as $40 \%$ (very low birth weight $2 \%-30 \%$, extremely low birth weight $12 \%-50 \%$ ), and neurodevelopmental impairment is common among survivors (extremely low birth weight 57\%). ${ }^{84-88}$ Because invasive fungal infections are common and extremely difficult to diagnose, prevention (decrease of risk factors that contribute to increased colonization and concentration of fungal organisms like maternal vertical transmission or nosocomial acquisition) and antifungal prophylaxis should be considered. ${ }^{89}$

\section{Parasitic enteritis - protozoan (Table IC)}

Some waterborne protozoan parasites induce enteritis through their membrane-associated functional structures and virulence factors that alter host cellular molecules and 
signaling pathways, leading to structural and functional lesions in the intestinal barrier. ${ }^{90}$

Cryptosporidium parvum has a high infectivity with significant enteric disease: rarely is asymptomatic. There have been reported cases of infection in the first month of life; the passage of the maternal antibodies and breastfeeding are a protective factor against infection. ${ }^{91}$

Giardiasis is one of the intestinal protozoa that cause public health problems in most resource-constrained nations, as well as some resource-rich countries. Many infected persons can be asymptomatic, leading to difficulties in the eradication and control of this parasite due to the number of potential carriers, such as school children. Giardia lamblia is observed almost three times more in asymptomatic children than in symptomatic children. The first signs of acute giardiasis include nausea, loss of appetite and an upper gastro-intestinal uneasiness, followed or accompanied by a sudden onset of explosive, watery, foul-smelling diarrhea. Stools associated with Giardia infection are generally described as loose, bulky, frothy and/or greasy with the absence of blood or mucus, which may help distinguish giardiasis from other acute diarrheas. Other gastro-intestinal disturbances may include: flatulence, bloating, anorexia, cramps. The acute stage usually resolves spontaneously in a few days. Occasionally an acute infection will persist and lead to malabsorption, steatorrhea, loss of strength and weight loss. It has been estimated that about 200 million people are infected each year in Africa, Asia and Latin America. In the resource-rich countries the prevalence rate of giardiasis is $2-5 \%$. However, in resorce-constrained countries, Giardia lamblia infects children early in life thus a prevalence rate of $15-20 \%$ in children younger than 10 years is common. Children who are malnourished are more frequently infected..$^{92}$

Cryptosporidium and Giardia most often cause diarrhea in immunocompromised children or in children from resource-constrained nations, and diarrhea tends to be chronic in both settings. ${ }^{60,92,93}$

Although E histolytica generally causes bloody diarrhea, some studies have demonstrated that $E$ histolytica could also be responsible for watery diarrhea, particularly in infants. That nondysenteric diarrhea is a common presentation of amebiasis in children less than 2 years of age but it was also reported among children aged 2-12 years of age..$^{94,95}$

Isospora belli is an opportunistic protozoan more frequent in developing countries of tropical and subtropical regions and should be monitored in both immunocompromised and immunocompetent patients with gastrointestinal complaints such as abdominal pain, nausea, and diarrhea.

\section{Parasitic enteritis - helminths}

Several helminths can also cause diarrhea, and their importance depends on geographic location, climatic conditions, poor sanitation, unsafe drinking water, and the immune status of the child. ${ }^{6,60}$

Strongyloidiasis is an infection caused by the intestinal nematode Strongyloides stercoralis. Infected healthy individuals are usually asymptomatic; however, it can cause watery or chronic diarrhea, abdominal cramping, failure to thrive, and cachexia. It is potentially fatal in immunocompromised hosts, due to its capacity to cause an overwhelming hyperinfection. A screening assay for Strongyloides infection in suspected patients is needed for early detection and successful cure. ${ }^{96}$

Trichuris trichiura infections are widespread globally, with prevalence and intensity-of-infection peaks in school age. Nevertheless, as soon as infants start to explore their environment, thus coming into contact with contaminated soil, they are at risk of infection according to the levels of transmission in the area. The pathogen can cause inflammatory damage to mucosa, bloody diarrhea, iron deficiency, and anemia.

\section{Diagnostic aspects}

Most children with gastroenteritis do not require any laboratory investigations. Many infants and children experience brief episodes of diarrhea, and are managed by their parents without seeking professional advice. Even if advice is sought, health care professionals often consider that a clinical assessment is all that is required, and laboratory investigations are not undertaken. ${ }^{4}$ However, there may be particular circumstances when investigations may be helpful in diagnosis. Frequently the signs and symptoms are not sufficient to make an etiological diagnosis as they often are nonspecific. The localization of the pathogen in the small intestine or in the colon, the characteristics of the feces (Table 2), the clinical history of the disease, and environmental risk factors can support the diagnostic evaluation. It would be also important to be aware of any history of recent contact with someone with acute diarrhoea and/or vomiting and exposure to a known source of enteric infection (possibly contaminated water or food) or a recent travel abroad. ${ }^{4}$

Severe watery diarrhea in the absence of mucus, pus, or blood suggests secretory diarrhea or malabsorption (such as by noninvasive Vibrio cholera, ETEC, or by rotavirus, adenovirus, or astrovirus), while the presence of blood and mucus are more indicative of an invasive germ, such as Salmonella, Shigella, Campylobacter jejuni, or Yersinia enterocolitica. ${ }^{60}$ The presence of vomiting and fever with diarrhea is nonspecific and cannot help in the diagnosis. ${ }^{4}$ It would be also important to be aware of any history of recent contact with 
Table 2 Characteristics of stool, intestinal segment-damaged, microorganisms involved

\begin{tabular}{lll}
\hline Feature of feces & Small intestine & Colon \\
\hline Appearance & Liquid & $\begin{array}{l}\text { Mucus and/or } \\
\text { with blood }\end{array}$ \\
Volume & Abundant & Poor \\
Frequency & Increase & Large increase \\
Blood & +- & +++ \\
$\mathrm{pH}$ & $<5.5$ & $>5.5$ \\
Reducing substances & Positive & Negative \\
Fecal leukocytes & $<5$ per field & $>$ I0 per field \\
Blood leukocytes & Normal & Possible leukocytosis \\
Microorganism & Virus & Invasive bacteria \\
& Adenovirus & Aeromonas spP \\
& Astrovirus & Campylobacter spP \\
& Calicivirus & ElEC - EHEC \\
& Rotavirus & Salmonella spP \\
& & Shigella spp \\
& & Plesiomonas spP \\
& & Yersinia spP \\
& Enterotoxigenic & Bacterial toxins \\
& bacteria & Clostridium difficile \\
& Clostridium perfringens & \\
& Cholera spP & \\
& ETEC & Parasites \\
& Vibrio spp & Entamoeba \\
& Giardia spp & organism \\
\hline
\end{tabular}

Note: @ 2009 Biomedia. Reproduced with permission from Caramia G, Ruffini E, Salvatori P. Infectious gastroenteritis. Neonatal Infectious Diseases Study Group of the Italian Society of Neonatology. Manual of Neonatal Infectious Diseases. Milan: Biomedia; 2009. ${ }^{55}$

someone with acute diarrhea and/or vomiting and exposure to a known source of enteric infection (possibly contaminated water or food), or recent foreign travel. ${ }^{4}$ Systemic symptoms (bacteremia, sepsis, spreading to other organs such as lungs, bones, and meninges) may variously complicate gastrointestinal infection by Salmonella, Shigella, Yersinia, and Campylobacter. C. difficile can be detected in stool specimens of many healthy children under the age of 1 year and a few percent of adults. Although these data support the potential for endogenous sources of human infection, there was early circumstantial evidence to suggest that this pathogen could be transmissible and acquired from external sources ${ }^{97}$ Therefore the possibility of other disorders would require careful consideration in such cases of diarrhea and/or vomiting as shown in Table 3.

\section{Laboratory diagnosis}

Regarding collection and transport of stool specimens, for stool culture for bacterial pathogens: one stool specimen is sufficient in most cases:
- C. difficile toxin testing: one stool specimen is sufficient in most cases.

- ova and parasite testing: specimen must be submitted in an appropriate preservative (sodium acetate-acetic acidformalin fixative).

- viral pathogens: stool for viral pathogens are not routinely tested; for a suspected outbreak of viral gastroenteritis, one stool specimen submitted in a sterile container is sufficient in most cases.

For the investigation of bacterial pathogens, stool specimens should be delivered to the laboratory as soon as possible, as a delay may compromise bacterial pathogen recovery. A single stool specimen, properly collected and promptly submitted, will identify most patients with a bacterial pathogen. Additional stool specimens need to be submitted if the culture results are negative, symptoms persist, and other causes cannot be found. If there are concerns regarding timing or transport of the specimen, consult the laboratory.

Table 3 Differential diagnosis

\begin{tabular}{ll}
\hline $\begin{array}{l}\text { Enzymatic and metabolic } \\
\text { disorders }\end{array}$ & $\begin{array}{l}\text { Anatomical defects } \\
\text { Hirschsprung's disease } \\
\text { malabsonital glucose-galactose }\end{array}$ \\
$\begin{array}{l}\text { Congenital disaccharidase defect } \\
\text { Intestinal lymphangiectasia } \\
\text { (lactase, isomaltase-saccaridasi) }\end{array}$ & $\begin{array}{l}\text { Primary immune disorders } \\
\text { Secondary malabsorption }\end{array}$ \\
$\begin{array}{l}\text { of monosaccharides and } \\
\text { disaccharidases (gastrointestinal }\end{array}$ & Thymic dysplasia \\
surgery, infections, intolerance & Enteropathy associated with \\
HIV-I
\end{tabular}

to soy protein)

Congenital chloridorrea

Congenital defect of the $\mathrm{Na}^{+} / \mathrm{H}^{+}$

exchanger

Congenital bile acid

malabsorption

Congenital defect

of enterochinasi

Cystic fibrosis

Shwachman syndrome

Physiological pancreatic

amylase deficiency

Enteropathic acrodermatitis

Wolman's disease

Abetalipoproteinemia

Adrenal insufficiency

Intestinal hormone hypersecretion

Transcobalamin II deficiency

Hereditary tyrosinemia

Methionine malabsorption

Congenital microvillous atrophy

Inflammatory disorders

Intolerance to cow's milk protein

Intolerance to soy protein

Regional enteritis

Ulcerative colitis

Hypoparathyroidism

Hyperparathyroidism

Various

Phototherapy for

hyperbilirubinemia

Familial dysautonomia

Familial enteropathy

Diarrhea from medications

(antibiotics, etc)

Necrotizing enterocolitis

Note: (c) 2009 Biomedia. Reproduced with permission from Caramia G, Ruffini E, Salvatori P. Infectious gastroenteritis. Neonatal Infectious Diseases Study Group of the Italian Society of Neonatology. Manual of Neonatal Infectious Diseases. Milan: Biomedia; 2009.55 
For physical and chemical study of feces, fecal $\mathrm{pH}$ less than or equal to 5.5 or the presence of reducing substances is a sign of intolerance to carbohydrates, mostly secondary to viral infection.

For microscopic examination of stool, the presence of leukocytes is suggestive of an enteroinvasive infection, although the absence of leukocytes cannot exclude it. However, infections mediated by enterotoxins (ETEC, Vibrio cholerae, and viruses) have no white blood cells in stool.

For fecal culture, various culture media are used to isolate the bacteria. The clinical history, physicochemical characteristics of the stool, and laboratory tests thus allow the choice of an appropriate culture medium. In the presence of clinical signs and leukocytes in the stool, it is always necessary to perform culture for Salmonella, Shigella, and Campylobacter. If stool cultures are not performed within 2 hours of sample collection, it is necessary to keep the stool at $4^{\circ} \mathrm{C}$.

Blood cultures are examined for evidence of bacteremia.

Research of bacterial toxins is conducted through enzyme-linked immunosorbent assay (ELISA). ${ }^{42}$ The fecal rotavirus antigen is examined through ELISA and latex agglutination test; search of adenovirus fecal antigen is performed using ELISA. ${ }^{98}$

Polymerase chain reaction (PCR) or other molecular investigations are performed for viral research, especially on stools for norovirus, adenovirus, sapovirus, and human bocavirus, and PCR of stool and blood is used for the detection of enteroviruses. ${ }^{63}$ A Providencia genus-specific PCR method has been developed, and its specificity and sensitivity was evaluated to be $100 \%$ with various bacterial strains. ${ }^{99}$ Recently, PCR methods have been applied to investigate the prevalence of the virulence genes specific for five major pathogroups of diarrheagenic Escherichia coli in primary cultures from feces of animals slaughtered for human consumption in Burkina Faso that revealed the common occurrence of the diarrheal virulence genes in feces of food animals. ${ }^{100}$ Another study investigated using PCR for the incidence, antimicrobial resistance, and genetic relationships of EPEC in children with diarrhea. ${ }^{101}$

Regarding parasitic infection and study of trophozoites or oocysts, antigen detection of stool through ELISA is used; the serological study can be helpful in rare systemic infections. ${ }^{60,82,91}$

For intestinal infection by enteroinvasive agents, it is possible to find low blood levels of albumin and high levels of alpha-1-antitrypsin in the stool, and an index of extended intestinal inflammation with dispersion of proteins. $^{22}$

\section{Preventive aspects}

Parents, caregivers, and children should be informed that it is possible to prevent the spread of gastroenteritis using some simple rules:

- wash hands with soap and water, especially after using toilet or changing diapers and before preparing, serving, or eating food

- do not share towels used by infected children

- children should not attend any school or other child-care facility while they have gastroenteritis; they can go back to school from at least 48 hours after the last episode of diarrhea or vomiting

- children should not use swimming pools for 2 weeks after the last episode of diarrhea ${ }^{102,103}$

- implementing rotavirus vaccination: the new rotavirus vaccines are safe and reduce the severity of infection and prevent deaths, but they do not prevent all cases of rotavirus diarrhea. ${ }^{104}$

Two live, oral, attenuated rotavirus vaccines were licensed in 2006: a pentavalent bovine-human recombinant vaccine and a monovalent human rotavirus vaccine. Both vaccines have demonstrated good safety and efficacy profiles in large clinical trials in resource-rich countries and in Latin America. ${ }^{105,106}$ Immunization against rotavirus is recommended in Europe and the US. ${ }^{107,108}$

The protective effects of breastfeeding against gastroenteritis infections have been demonstrated in several studies. ${ }^{109,110}$ Antibacterial substances, such as lactoferrin, lysozyme, phagocytes, and specific secretory immunoglobulins plays a protective role. ${ }^{111}$ The ligand-specific action of $\kappa$-casein inhibits Helicobacter pylori adherence to the gastric mucosa. Human milk also has antiviral action through the lactoferrin and products of digestion of lactoferrin and milk fatty acids. ${ }^{12}$ All of these elements suggest that exclusive breastfeeding contributes to protection against common infections during infancy and lessens the frequency and severity of infectious episodes. ${ }^{113}$ Breastfeeding promotes the colonization of the intestinal ecosystem with a predominance of bifidobacteria and lactobacilli (probiotics) rather than coliforms, enterococci, and bacteroides that characterize the intestinal microflora of infants fed with formula. ${ }^{114}$ Some authors have demonstrated that the use of formulas supplemented with probiotics (Bifidobacterium lactis and Lactobacillus GG) have decreased the incidence (up to $57 \%$ ) and severity of diarrhea. The probiotics, also 
defined as food supplements, improve intestinal balance, have beneficial effects on health, and are able to balance the intestinal ecosystem and reduce the duration and severity of diarrheal infections, especially in the course of rotavirus infections. The probiotics in the intestine determine resistance to colonization by other potentially pathogenic microbes through mechanisms of competition or inhibition, and the effects are expressed both on nonspecific innate and acquired immunity. ${ }^{115}$ Lactobacillus rhamnosus GG (LGG) is considered particularly effective in the management of AGE; this is confirmed by a recent Cochrane review documenting that LGG reduced the duration of diarrhea, mean stool frequency on day 2 , and the risk of diarrhea lasting $\geq 4$ days. ${ }^{1,116}$

According to a recent Cochrane review, Saccharomyces boulardii reduces the risk of diarrhea lasting $\geq 4$ days, and a more recent review confirmed that $S$. boulardii significantly reduced the duration of diarrhea and hospitalization. A recent randomized controlled trial evaluated the efficacy of treatment with Lactobacillus reuteri DSM 17938 compared with placebo: the administration of $L$. reuteri reduced the duration of watery diarrhea, the risk of diarrhea on days 2 and 3, and the relapse rate of diarrhea. ${ }^{1}$ It has been suggested that probiotics may decrease infant mortality and nosocomial infections because of their ability to suppress colonization and translocation of bacterial pathogens in the gastrointestinal tract. Several meta-analyses evaluating probiotics in preterm infants suggest a beneficial effect for the prevention of necrotizing enterocolitis and death, but less for nosocomial infection. L. reuteri may reduce these outcomes because of its immunomodulation and bactericidal properties. A large, double-blinded, randomized controlled trial (RCT) using L. reuteri was performed to test this hypothesis in preterm infants. This study suggested that although $L$. reuteri did not appear to decrease the rate of death or nosocomial infection, the trends suggest a protective role consistent with what has been observed in the literature: a protective role for mortality, nosocomial infection, and necrotizing enterocolitis. Feeding intolerance and duration of hospitalization were significantly decreased in premature infants less than $1500 \mathrm{~g} .{ }^{117}$ The use of formulas supplemented with probiotics (particularly Bifidobacterium lactis and Lactobacillus GG) seems to decrease the incidence (up to $57 \%$ ) and severity of infectious acute diarrhea. Symbiotics, a combination of prebiotics and probiotics that beneficially affect the host by improving survival and implantation of live microbial dietary supplements in the gastrointestinal tract, has recently been evaluated by two European RCTs for the management of AGE. These studies are promising, but presently it would not be appropriate to recommend the use of symbiotics until confirmatory data are available. ${ }^{1}$

\section{Treatment \\ Rehydration therapy}

Dehydration is probably the main complication of gastroenteritis in childhood. WHO classification of patients' hydration status is based on the presence of symptoms and signs. The presence of one of these signs or symptoms immediately classifies the patient as a more severe case. Table 4 summarizes the WHO management of rehydration. ${ }^{118,119}$

All moderate and severe patients require close monitoring, but patients at the extreme ages of life, especially children under 18 months, require meticulous observation and immediate measures if their condition worsens. According to current WHO recommendations, oral rehydration therapy (ORT) is considered the treatment of choice to replace fluid and electrolyte losses caused by diarrhea in children with mild to moderate dehydration. Intravenous rehydration is the treatment of choice in cases of failure of ORT, and it has to be reserved for patients with severe dehydration or who eliminate more than $10-20 \mathrm{~mL} /$ $\mathrm{kg} /$ hour. In the $1960 \mathrm{~s}$, efforts by young scientists and researchers led to the development of ORT for the treatment of dehydration that often accompanies acute attacks of diarrhea. Many members of the research team responsible for this discovery were associated with noteworthy universities and medical research centers in the US. The goal of their research was to devise effective therapies for cholera-induced diarrhea; as a result of their hard work, they developed a new framework for treatment that would soon be adopted throughout the developing world as a key element in the overall strategy to combat acute diarrhea and the potentially fatal dehydration that accompanies the disease. In an article published in 1968 in the Lancet, it was confirmed that cholera patients could be rehydrated orally with a simple solution of water, salt, and sugar, and equally importantly that field staff could easily be trained to administer the therapy. As stated in the article, ORT also offers a practical treatment for large numbers of patients in the developing world who do not have access to traditional intravenous drip therapy. At first, studies on the efficacy of ORT, when compared with intravenous therapy (IVT), were conducted only in patients with cholera. ${ }^{120-122}$ Following that, other studies established the effectiveness of ORT in children with acute diarrhea from other causes. ${ }^{123}$ Some trials also compared the effectiveness of oral rehydration 


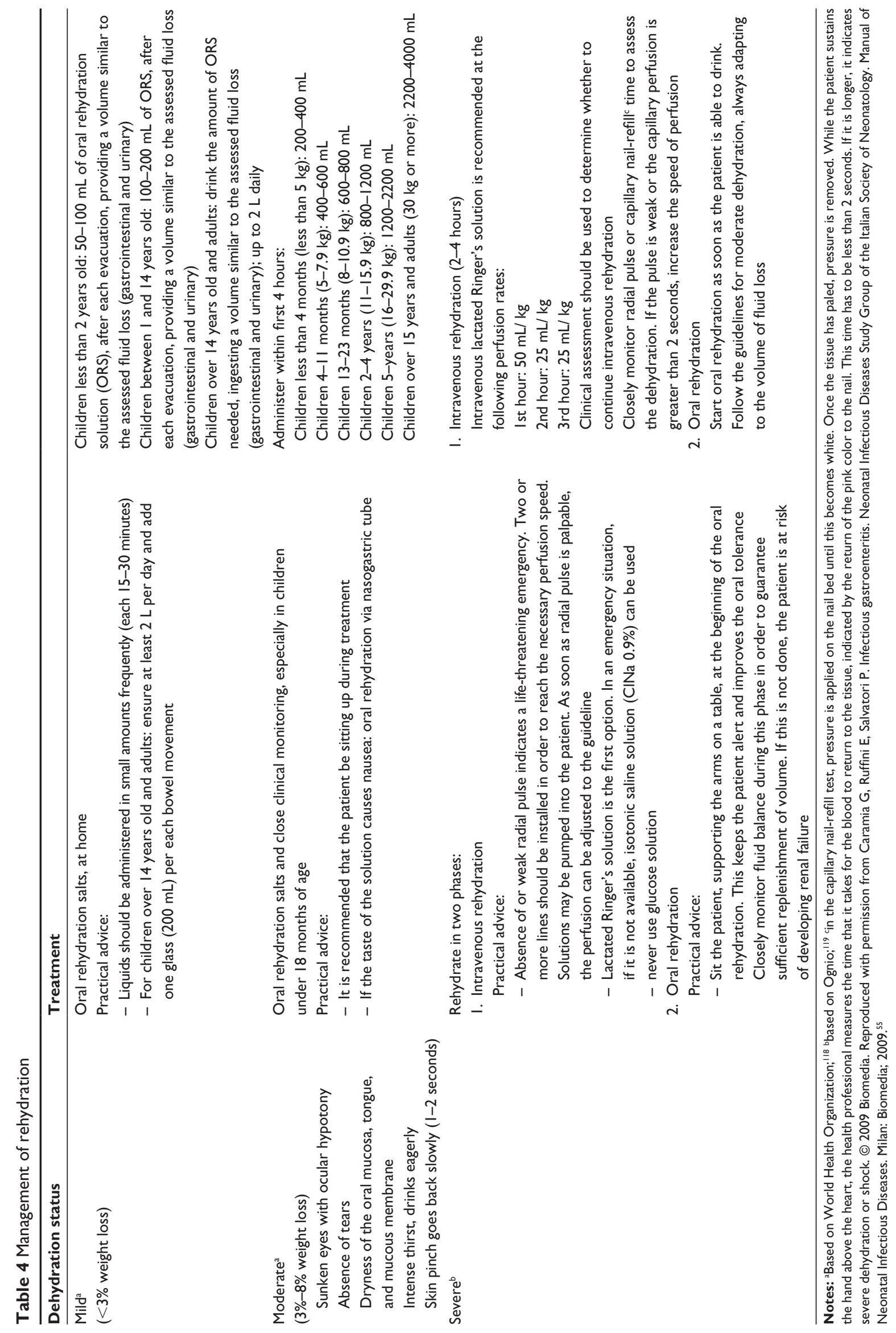


with IVT in children with different degrees and types of dehydration (mild, moderate, severe, and hypernatremic dehydration), and they concluded that the use of ORS to rehydrate children is safe and that there are no significant differences in incidences of hyponatremia, hypernatremia, mean duration of diarrhea, weight gain, or total fluid intake if compared with IVT. In terms of outcomes, ORT was associated with a higher risk of rehydration failure, while babies treated with IVT had a significantly longer stay in hospital and a higher risk of phlebitis, but no statistically significant differences were seen. ${ }^{124}$ The main reason for this failure is that ORS neither reduces the frequency of bowel movements and fluid loss nor shortens the duration of illness; moreover, the unpalatability of regular ORS (strong salty taste) also decreases this acceptance. However, the most important aspect of treatment of gastroenteritis is the water and electrolyte balance. It must be adjusted according to serum electrolytes, body water content (greater the younger the child), and the water demand must be calculated on the weight of the newborn infant (Table 5A and B). Different ORS are now commercially available (Table 6). ${ }^{125}$ Recently, some companies have added probiotics to the saline solution to obtain a quick balance of intestinal bacterial flora. The infant should be monitored closely to check the status of nutrition and hydration. Infants with moderate dehydration, suspected infected by EHEC, with bloody diarrhea, or systemic symptoms should be hospitalized. These newborns are at high risk of secondary complications. During ORT, milk-feeding is often temporarily suspended. Among all the oral solutions, the ideal one has a low osmolarity (210-250 mOsm/L) and a sodium content of 50-60 $\mathrm{mmol} / \mathrm{L}$ to avoid high levels of serum sodium. The solution should be administered frequently and in small amounts to prevent vomiting. Initial oral rehydration is $50-100 \mathrm{~mL} / \mathrm{kg}$ in the first 4 hours. ${ }^{126}$ Also consider giving the ORS via a nasogastric tube if patients are unable to drink it or if they vomit persistently and to monitor them by regular clinical assessment. In cases of failure of oral rehydration, it is necessary to establish an appropriate parenteral rehydration fluid and electrolyte solutions (Table 7). ${ }^{127}$

\section{Antisecretory drugs}

Pediatric presentations of racecadotril were first authorized in France in 1999, and today it is approved and widely used in seven European countries (France, Spain, Italy, Portugal, Greece, Bulgaria, and Romania) and outside Europe. ${ }^{128}$ This antisecretory drug is a peripherally acting enkephalinase inhibitor that reduces intestinal water and electrolyte hypersecretion acting on the enkephalins (neurotransmitters of the gastrointestinal tract) through the selective stimulation of delta receptors inhibit adenylate cyclase activity by reducing the intracellular concentration of cAMP, thus reducing the secretion of water and electrolyte in the intestinal lumen. The result is a reduction of water and electrolyte secretion without changes in intestinal motility. Moreover, the action of racecadotril takes place only when there is a hypersecretion and has no effect on the activity secretory baseline. New data have reconfirmed that racecadotril is an effective adjunctive therapy to oral rehydration in watery diarrhea. ${ }^{1}$ A recent individual patient data meta-analysis ${ }^{129}$ assessed the efficacy of the use of racecadotril as an adjunct to ORS compared with ORS alone or with placebo. Raw data from nine RCTs involving 1348 children aged 1 month to 15 years with AGE were available for the analysis. Two trials compared the effect of racecadotril with placebo ${ }^{130,131}$ with no treatment (two RCTs), or with kaolin-pectin (two RCTs). Compared with placebo, racecadotril significantly reduced the duration of diarrhea after inclusion. Almost two times more patients recovered at any time in the racecadotril group vs the placebo group $(P<0.001)$. There were no interactions between treatment and dehydration, rotavirus infection, type of study (outpatient/inpatient), or country. In the studies evaluating inpatients, the ratio of mean stool output racecadotril/placebo was reduced $(P<0.001)$. In outpatient studies, the number of diarrheal stools was lower in the racecadotril group $(P<0.001)$. In the responder analysis (defined as a duration

Table 5A Content and distribution of body fluids according to age

\begin{tabular}{|c|c|c|c|c|c|c|}
\hline & Premature & Infant & I year old & 3 years old & 9 years old & Adult \\
\hline Weight (kg) & 1.5 & 3 & 10 & 15 & 30 & 70 \\
\hline Body surface area $\left(\mathrm{m}^{2}\right)$ & 0.15 & 0.2 & 0.5 & 0.6 & I & 1.7 \\
\hline Liquid body weight (\%) & 80 & 78 & 65 & 60 & 60 & 60 \\
\hline Extracellular fluid (\%) & 50 & 45 & 25 & 20 & 20 & 20 \\
\hline Intracellular fluid (\%) & 30 & 33 & 40 & 40 & 40 & 40 \\
\hline
\end{tabular}

Note: (c) 2009 Biomedia. Reproduced with permission from Caramia G, Ruffini E, Salvatori P. Infectious gastroenteritis. Neonatal Infectious Diseases Study Group of the Italian Society of Neonatology. Manual of Neonatal Infectious Diseases. Milan: Biomedia; 2009.55 
Table 5B Daily water demand in relation to age

\begin{tabular}{|c|c|c|}
\hline Bod & rs & $\begin{array}{l}\text { Flow rate } \\
\text { administration/hour }\end{array}$ \\
\hline & & \\
\hline & $\begin{array}{l}1000 \mathrm{~mL}+ \\
\text { for each kg }\end{array}$ & $\begin{array}{l}40 \mathrm{~mL} / \mathrm{kg} / \\
\times \text { (body n }\end{array}$ \\
\hline Children $>20 \mathrm{~kg}$ & $\begin{array}{l}1500 \mathrm{~mL}+20 \mathrm{~mL} / \mathrm{kg} \\
\text { for each } \mathrm{kg} \text { above } 20 \mathrm{~kg}\end{array}$ & $\begin{array}{l}60 \mathrm{~mL} / \mathrm{kg} / \mathrm{h}+\mathrm{I} \mathrm{mL} / \mathrm{kg} / \mathrm{h} \\
\times(\text { body weight }-20 \mathrm{~kg} \text { ) }\end{array}$ \\
\hline
\end{tabular}

Note: (C) 2009 Biomedia. Reproduced with permission from Caramia G, Ruffini E, Salvatori P. Infectious gastroenteritis. Neonatal Infectious Diseases Study Group of the Italian Society of Neonatology. Manual of Neonatal Infectious Diseases. Milan: Biomedia; 2009.55

of diarrhea of less than 2 days), the proportion of responders was significantly higher in the racecadotril group compared with the placebo group. By adjusting for dehydration and rotavirus, the absolute risk difference was $24.7 \%$ ( $95 \%$ confidence interval 19.8-29.7), and the associated number needed to treat was four. The secondary need for care in outpatients was significantly in favor of racecadotril in two studies. Also, the need for IVT was lower in the racecadotril group compared with the placebo group. There was no difference in the incidence of adverse events between the groups. The results of this recent meta-analysis support the use of racecadotril as an adjunct to ORS for the management of AGE in children. In addition, the safety of racecadotril in children has been demonstrated in clinical studies, including a large pre- and postaccess study showing that racecadotril has a favorable adverse-event profile in children. ${ }^{128-130}$ Despite racecadotril's proven safety and efficacy in treating acute watery diarrhea, its cost-effectiveness for infants and children has not yet been determined in Europe. ${ }^{128}$ The UK model highlights the potential savings arising from reduction in diarrhea duration and avoidance of reconsultation and referral rates in children with diarrhea. ${ }^{128}$

\section{Antiemetics}

Children presenting with AGE often have high levels of vomiting that can interfere with the oral rehydration process, which could limit the success of the oral therapy. Ondansetron is widely used in the pediatric emergency department for vomiting and AGE; it can help with the successful delivery of ORT, thereby reducing the need to treat with IVT. A recent study evaluated the spectrum of diagnoses for which ondansetron is used in the pediatric emergency room. Medical records of patients 3 months to 18 years of age given ondansetron for 2 years were retrospectively reviewed. Patients without a primary discharge diagnosis of vomiting or gastroenteritis were defined as non-gastroenteritis, and they were compared to the gastroenteritis group. The non-gastroenteritis group includes $38 \%$ of the subjects, and they were older ( 8.3 vs 4.3 years) than the gastroenteritis patients. The most common primary diagnoses for non-gastroenteritis discharged patients were fever (15\%), abdominal pain/tenderness (13\%), head injury/concussion (7\%), pharyngitis $(6 \%)$, viral infection $(6 \%)$, migraine variants $(5 \%)$, and otitis media (5\%). Although ondansetron is a widely accepted treatment for gastroenteritis

Table 6 Composition of the main oral rehydration solutions on the market in Europe

\begin{tabular}{|c|c|c|c|c|c|c|c|c|c|}
\hline & $\begin{array}{l}\text { Glucose } \\
\mathrm{mmol} / \mathrm{L}\end{array}$ & $\begin{array}{l}\mathrm{Na} \\
\mathrm{mEq} / \mathrm{L}\end{array}$ & $\begin{array}{l}\mathrm{K} \\
\mathrm{mEq} / \mathrm{L}\end{array}$ & $\begin{array}{l}\mathrm{Cl} \\
\mathrm{mEq} / \mathrm{L}\end{array}$ & $\begin{array}{l}\mathrm{HCO}_{3} \mathrm{I} \\
\text { citrate } \mathrm{mEq} / \mathrm{L}\end{array}$ & mOsm/L & Kcal/L & Aroma & Probiotics \\
\hline WHO (1984/2002) & $110 / 75$ & $90 / 75$ & 20 & 80 & $30 / 8-12$ & $311 / 245$ & 80 & No & No \\
\hline ESPGHAN (I989//997) & $74-111$ & 60 & 20 & $>25$ & 20 & $200-250$ & $52-80$ & No & No \\
\hline Dicodral forte & 111 & 90 & 20 & 80 & 30 & 331 & 80 & No & No \\
\hline Dicodral 60 & 90 & 60 & 20 & 37 & I4 citrate & 211 & 80 & Banana & No \\
\hline Dicodral & 111 & 30 & 20 & 40 & 10 & 211 & 80 & No & No \\
\hline Floridral & 83 & 60 & 20 & 37 & 14 citrate & 214 & 80 & Banana & $\mathrm{LGG} \mathrm{CFU}=5 \times 10^{9}$ \\
\hline GES 60 & 108 & 60 & 20 & 50 & I4 citrate & 270 & 80 & No & No \\
\hline Idraton 245 & 75 & 75 & 20 & 65 & 10 citrate & 245 & 79.1 & Orange & No \\
\hline Idravita & 120 & 60 & 20 & 50 & 10 citrate & 230 & 80 & Banana & No \\
\hline Prereid & 77 & 50 & 20 & 40 & 10 & 200 & 79.35 & Citrus & No \\
\hline Prereid, liquid & 1.91 & 50 & 20 & 57 & 66 & 230 & 80 & Citrus & No \\
\hline Reidrax & 75 & 60 & 20 & 60 & 10 citrate & 225 & 60.8 & No & No \\
\hline Reuterin idro & 83 & 61 & 20 & 46 & II & 220 & 60 & No & $\begin{array}{l}\text { L. reuteri DSM } \\
17938 \mathrm{CFU}=10^{8}\end{array}$ \\
\hline Reuterin brick & 61 & 58.5 & 19.2 & 44.3 & - & 230 & 45 & Apricot & $\begin{array}{l}\text { L. reuteri DSM } \\
17938 \mathrm{CFU}=10^{8}\end{array}$ \\
\hline Home solution & \multicolumn{9}{|c|}{ Water I liter, sugar I spoon ( $19 \mathrm{~g})$, salt I teaspoon ( $3 \mathrm{~g})$, a pinch of bicarbonate $(0.5 \mathrm{~g})$} \\
\hline
\end{tabular}


Table 7 Treatment algorithm for acute gastroenteritis

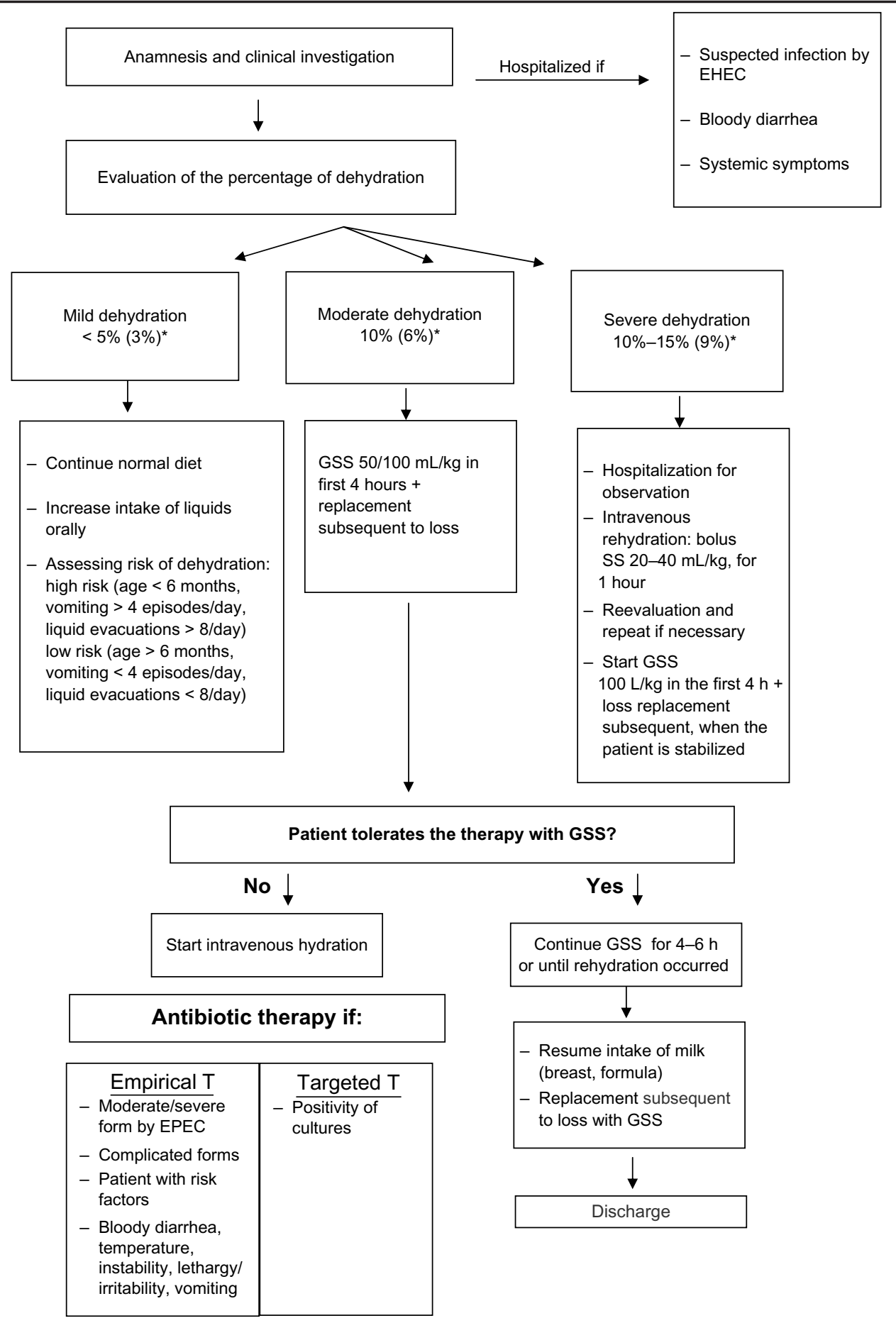

Note: *Weight loss in children after the first year of age.

Abbreviations: GSS, glucose-saline solution; SS, saline solution; T, therapy; ETEC, Enterotoxigenic Escherichia coli; EPEC, Enteropathogenic E. coli; EIEC, Enteroinvasive E. coli; EAEC, Enteroaggregative E. coli; EHEC, Enterohemorrhagic E. coli; EPEC, Enteropathogenic E. coli.

in children $-62 \%$ of total use - this study identifies a broader spectrum of primary diagnoses for which ondansetron is being used. ${ }^{132}$ Another study used RCTs comparing antiemetics with placebo or no treatment in children and adolescents under the age of 18 years, for vomiting due to gastroenteritis. The proportion of patients with cessation of vomiting in 24 hours was $58 \%$ with intravenous ondansetron, $17 \%$ placebo, and $33 \%$ in the metoclopramide group $(P=0.039)$. In this case, the authors' conclusions were that oral ondansetron increased the proportion of patients who had ceased vomiting and reduced the number needing intravenous rehydration and so immediate hospital admissions. ${ }^{1,133}$ Today, it is still unclear if in spite of an improvement in the vomiting, ondansetron worsens diarrhea. Some trials report a statistically significant increase in its 
frequency as an adverse event. In Cochrane reviews, diarrhea was reported as a side effect in four of the five ondansetron studies. ${ }^{133-135}$ According to WHO, of the antiemetics available, those with the greatest evidence of efficacy in the prevention of nausea and vomiting (particularly in the treatment of postsurgery nausea and vomiting) were ondansetron and dexamethasone, ondansetron as first-line treatment with the addition of dexamethasone as required. ${ }^{136}$

\section{Zinc supplements}

Zinc is an important trace element, as over 300 enzymes require zinc for their activation and nearly 2000 transcription factors require zinc for gene expression. Zinc is essential for epithelial barrier integrity, tissue repair, cell-mediated immunity, and immune function. Zinc as an antioxidant and antiinflammatory agent is effective in gastrointestinal structure and function. ${ }^{137}$ Diarrhea is associated with significant zinc loss, and the use of zinc supplements can reduce the duration and severity of diarrhea in children. In areas where the prevalence of zinc deficiency or the prevalence of moderate malnutrition is high, zinc may be of benefit in children aged 6 months or more. The current evidence does not support the use of zinc supplementation in children below 6 months of age. ${ }^{138}$

The WHO has recommended zinc supplementation in children with gastroenteritis. Supplements should be started at the beginning of the symptoms. Recommended doses and duration:

- for children less than 6 months of age, $10 \mathrm{mg}$ daily for 10 days

- for children from 6 months to 5 years of age, $20 \mathrm{mg}$ daily for 10 days.

This therapy decreases the severity and reduces the number of episodes of diarrhea occurring within 2-3 months following the intake of zinc. ${ }^{139}$

\section{Probiotics}

The physiological composition of intestinal microflora is essential to maintain an appropriate balance of microbiota and the intestinal barrier. Probiotics, also defined as food supplements, improve the intestinal microbial balance of the host, have beneficial effects on health, prevent outbreaks of community-acquired diarrhea, reduce colonization of infants with pathogenic microorganisms, and reduce the duration and severity of diarrheal infections, balancing the intestinal ecosystem. In large clinical trials, Lactobacillus reuteri, LGG, and Saccharomyces boulardii have shown the best therapeutic effects (reducing mean duration and frequency of watery diarrhea and number of watery stools per day, and improving stool's consistency). ${ }^{140-142}$ Particularly, a recent randomized double blind study carried out in three Italian pediatric centers showed that $L$. reuteri DSM 17938, taken together with a standard ORS, significantly reduced the duration of watery diarrhea compared with placebo $(2.1 \pm$ 1.7 days vs $3.3 \pm 2.1$ days, $P<0.03$ ). On days two and three of treatment, watery diarrhea persisted in $82 \%$ and $74 \%$ of the placebo and $55 \%$ and $45 \%$ of the $L$. reuteri recipients, respectively $(P<0.01, P<0.03)$. Moreover, children receiving $L$. reuteri DSM 17938 had a significantly lower relapse rate of diarrhea $(15 \%$ vs $42 \%, P<0.03) .{ }^{143}$ The European Society of Gastroenterology, Hepatology, and Nutrition and the National Institute for Health and Clinical Excellence have suggested the use of probiotic strains with proven efficacy and in appropriate doses for the management of children with acute gastroenteritis as an adjunct to rehydration therapy. ${ }^{144,145}$ Probiotics and symbiotics are of interest as they elicit healthpromoting properties to the host, release various soluble low-molecular-weight molecules of different nature (surface and exogenous proteins, peptides, amines, lectins, sirtuines, nucleases, other enzymes, bacteriocines, fatty and amino acids, lactones, nitric oxide, etc), are able to interact with corresponding cell receptors, to reply quickly by induction of special sets of genes, to support stability of host genome and microbiome, to modulate epigenomic regulation of gene phenotypic expression, and to ensure information exchange in numerous bacterial and bacteria-host systems. All this plays an important role in the control for many physiological, biochemical, and genetic functions in supporting host health. Recently, probiotic L. reuteri strain ATCC PTA 6475 demonstrated the ability to potently suppress human tumor necrosis-factor production by lipopolysaccharide-activated monocytes and primary monocyte-derived macrophages from children with Crohn's disease: the primary mechanism of probiotic-mediated immunomodulation is transcriptional regulation. ${ }^{146}$ Other researchers have confirmed these results, and it has been shown that $L$. reuteri produce biologically active small compounds, previously unknown, that can modulate host mucosal immunity. The identification of bacterial bioactive metabolites and their corresponding mechanisms of action with respect to immunomodulation may lead to improved anti-inflammatory strategies for chronic immunomediated diseases. ${ }^{147}$

\section{Antibiotic therapy \\ Bacteria}

Most cases of AGE in children are viral, self-limited, and need only supportive treatment. Antibacterial therapy serves as an adjunct, to shorten the clinical course, eradicate causative organisms, reduce transmission, and prevent invasive com- 
plications. Selection of antibacterials to use in acute bacterial gastroenteritis is based on clinical diagnosis of the likely pathogen prior to definitive laboratory results. Antibacterial therapy should be restricted to specific bacterial pathogens and disease presentations. In general, infections with Shigella spp and Vibrio cholera should usually be treated with antibacterials, while antibacterials are only used in severe unresponsive infections with Salmonella, Yersinia, Aeromonas, Campylobacter, Plesiomonas spp, and Clostridium difficile. Antibacterials should be avoided in EHEC infection. ${ }^{18}$ There is no evidence of benefit for antibiotics in nontyphoidal Salmonella diarrhea in otherwise healthy people. The effects in very young people, very old people, and in people with severe and extraintestinal disease are not always so clear, and a slightly higher number of adverse events are noted in people who receive antibiotic treatment for nontyphoidal Salmonella diarrhea. ${ }^{149}$ However, empiric therapy may be appropriate in the presence of a severe illness with bloody diarrhea and stool leucocytes, and particularly in patients with risk factors (ill-fed or debilitated patients), the use of systemic antibiotics has been recommended (Table 8). ${ }^{148,150}$ The benefits and risks of adverse drug reactions should be weighed before prescribing antibacterials. Moreover, a major concern is the emergence of antibacterial-resistant strains due to the widespread use of antibacterial agents.

Aeromonas spp produce a $\beta$-lactamase that induces resistance to penicillin and first-generation cephalosporins. In fact, several studies have demonstrated a relatively high

Table 8 Bacterial gastroenteritis and antimicrobial active on germs responsible

\begin{tabular}{|c|c|c|}
\hline Pathogen & Sensitive antimicrobial & Indications for therapy \\
\hline Aeromonas spp & $\begin{array}{l}\text { - Ciprofloxacin ( } 250-350 \mathrm{mg}, 2 \text { every I2 hours) } \\
\text { - Cephalosporins III (cefotaxime } 25-80 \mathrm{mg} / \mathrm{kg} \text { IV every I2 hours) } \\
\text { - Meropenem ( } 20 \mathrm{mg} / \mathrm{kg} \text { IV every } 8 \text { hours) } \\
\text { - Aminoglycosides (gentamicin } 4 \mathrm{mg} / \mathrm{kg} \text { IV every } 24 \text { hours) }\end{array}$ & In invasive forms \\
\hline Campylobacter spp & $\begin{array}{l}\text { - Azithromycin ( } 5 \mathrm{mg} / \mathrm{kg} \text { every } 12 \text { hours or } 10 \mathrm{mg} / \mathrm{kg} \text { every } 24 \text { hours) } \\
\text { - Erythromycin ( } 10-15 \mathrm{mg} / \mathrm{kg} \text { IV every } 8 \text { hours) }\end{array}$ & In invasive forms \\
\hline Clostridium difficile & $\begin{array}{l}\text { - Metronidazole }(7.5-10 \mathrm{mg} / \mathrm{kg} \text { OS/IV every } 8 \text { hours }) \\
\text { - Vancomycin ( } 10 \mathrm{mg} / \mathrm{kg} \text { OS every } 6 \text { hours })\end{array}$ & $\begin{array}{l}\text { Therapy should be initiated only if diarrhea } \\
\text { persists after a suspension of antibiotic therapy }\end{array}$ \\
\hline Escherichia coli & $\begin{array}{l}\text { - Cephalosporins III (ceftriaxone } 50 \mathrm{mg} / \mathrm{kg} \text { IV every } 24 \text { hours) } \\
\text { - Aminoglycosides (amikacyn } 7.5 \mathrm{mg} / \mathrm{kg} \text { every } 8-12 \text { hours) (EPEC) } \\
\text { - Meropenem ( } 20 \mathrm{mg} / \mathrm{kg} \text { IV every } 8 \text { hours) (EPEC) } \\
\text { - Azithromycin ( } 5 \mathrm{mg} / \mathrm{kg} \text { every I2 hours or or } 10 \mathrm{mg} / \mathrm{kg} \text { every } 24 \text { hours) (EHEC) } \\
\text { - Ciprofloxacin ( } 250-350 \mathrm{mg} \text { every } 12 \text { hours) (ETEC; EAEC) } \\
\text { - Rifaximin (> } 12 \text { years: } 200 \mathrm{mg} \text { every } 8-12 \text { hours) (EAEC) }\end{array}$ & $\begin{array}{l}\text { If systemic complications. The use of antibiotics } \\
\text { increases the risk of hemolytic uremic syndrome } \\
\text { ) }\end{array}$ \\
\hline Helicobacter pylori & $\begin{array}{l}\text { - Amoxicillin (70 mg/kg every 8-12 hours) + } \\
\text { - Clarithromycin (7.7 mg/kg every } 12 \text { hours) }\end{array}$ & $\begin{array}{l}\text { Add one of the related drugs: omeprazole } 20 \\
\mathrm{mg} \text {, lansoprazole } 30 \mathrm{mg} \text {, pantoprazole } 40 \mathrm{mg} \text {, } \\
\text { rabeprazole } 20 \mathrm{mg} \text {, esomeprazole } 20 \mathrm{mg} \text { ) } \\
\text { every } 12 \text { hours }\end{array}$ \\
\hline Pleiomonas spp & $\begin{array}{l}\text { - Ciprofloxacin ( } 250-350 \mathrm{mg} \text { every } 12 \text { hours) } \\
\text { - Azithromycin ( } 5 \mathrm{mg} / \mathrm{kg} \text { or } 10 \mathrm{mg} / \mathrm{kg} \text { every } 12 \text { hours or } 10 \mathrm{mg} / \mathrm{kg} \text { every } 24 \text { hours) } \\
\text { - Trimethoprim-sulfamethoxazole (4-20 mg/kg orally every } 12 \text { hours) }\end{array}$ & In invasive forms \\
\hline Salmonella spp & $\begin{array}{l}\text { - Ampicillin or amoxicillin (100 mg/kg IV every } 6 \text { hours) } \\
\text { or cephalosporins III (ceftriaxone } 50 \text { mg/kg IV every } 24 \text { hours) }\end{array}$ & $\begin{array}{l}\text { In invasive forms. Therapy prolongs the carrier } \\
\text { state; however, recommended under } 3 \text { months } \\
\text { of age for the high incidence of bacteremia. } \\
3-5 \text { days if there is bacteremia, or I-4 weeks } \\
\text { if there is involvement of the meninges }\end{array}$ \\
\hline Shigella spp & $\begin{array}{l}\text { - Ciprofloxacin ( } 250-350 \mathrm{mg} \text { every } 12 \text { hours) } \\
\text { - Cephalosporins III (ceftriaxone } 50 \mathrm{mg} / \mathrm{kg} \mathrm{IV} \mathrm{every} 24 \text { hours) } \\
\text { - Azithromycin ( } 5 \mathrm{mg} / \mathrm{kg} \text { every } 12 \text { hours) }\end{array}$ & $\begin{array}{l}\text { In invasive forms. The treatment reduces } \\
\text { duration of illness, but does not prevent } \\
\text { complications }\end{array}$ \\
\hline Vibrio cholerae & $\begin{array}{l}\text { - Cephalosporins III (ceftriaxone } 50 \mathrm{mg} / \mathrm{kg} \text { IV every } 24 \text { hours) } \\
\text { - Ciprofloxacin ( } 250 \text {-350 mg every } 12 \text { hours) }\end{array}$ & $\begin{array}{l}\text { The treatment reduces duration of illness } \\
\text { and prevents dehydration. The antimicrobial } \\
\text { susceptibility patterns are constantly changing }\end{array}$ \\
\hline Yersinia spp & $\begin{array}{l}\text { - Cephalosporins III (ceftriaxone } 50 \mathrm{mg} / \mathrm{kg} \text { IV every } 24 \text { hours) } \\
\text { - Aminoglycosides (gentamicin } 4 \mathrm{mg} / \mathrm{kg} \text { IV every } 24 \text { hours) } \\
\text { - Meropenem ( } 20 \mathrm{mg} / \mathrm{kg} \text { IV every } 8 \text { hours) } \\
\text { - Ciprofloxacin ( } 250-350 \mathrm{mg} \text { every } 12 \text { hours) }\end{array}$ & Only in complicated cases \\
\hline
\end{tabular}

Abbreviations: OS, orally; IV, intravenous; ETEC, Enterotoxigenic E. coli; EPEC, Enteropathogenic E. coli; EAEC, Enteroaggregative E. coli; EHEC, Enterohemorrhagic E. coli. 
resistance rates for cephalothin and for trimethoprimsulfamethoxazole; low rates of resistance has been found to third generation cephalosporin (cefotaxime), to ciprofloxacin and to chloramphenicol. With high levels of resistance to many antibiotics, resistance of $A$. hydrophila to ciprofloxacin is still very low, which may suggest that ciprofloxacin and other quinolone class antimicrobials may be considered as potential drugs for the treatment of bacterial diarrhea caused by $A$. hydrophila. ${ }^{21,151,152}$

For Campylobacter jejuni, antibiotics are initiated in cases of febrile diarrheas, especially those believed to have moderate to severe disease. Considering the increased incidence of $C$. jejuni and the resistance of the great majority of isolated strains to quinolones, the administration of azithromycin empirically for acute diarrhea, when indicated, could be appropriate. ${ }^{153,154}$ Moreover, erythromycin treatment of acute $C$. jejuni diarrhea demonstrated antibacterial efficacy by reducing the mean number of days until first negative stool culture. ${ }^{4}$

According to recent studies, the management of Clostridium difficile infections involves three basic principles: supportive care, discontinuing the precipitating antibiotic(s), and the initiation of effective anti-C. difficile therapy. Discontinuation of the offending antibiotic may be sufficient for the resolution of mild symptoms and facilitates the reconstitution of the normal enteric flora. ${ }^{154}$ For mild-moderate $C$. difficile infection in children, metronidazole is the drug of choice, with efficacy similar to vancomycin. For severe infection, oral vancomycin with intravenous metronidazole is recommended. Linezolid also has a potential impact, and in adults, recurrence is less frequent with fidaxomicin than with vancomycin. ${ }^{155-158} \mathrm{~A}$ vaccine against $C$. difficile is desirable and being developed for prevention. ${ }^{159}$

Regarding Enterobacteriaceae, an antibiotic-susceptibility profile indicated that enteropathogens are generally susceptible to meropenem and ceftriaxone, followed by amikacin and ciprofloxacin. Almost all enteropathogens were resistant to ampicillin and amoxicillin. ${ }^{160}$

EPEC infection is primarily a disease of infants younger than 2 years of age, often contracted during travel in hot countries. In moderate-severe forms of gastroenteritis caused by EPEC in nurseries, the use of antibiotics such as imipenem, amikacin, gentamicin, and fluoroquinolone seem to be useful in reducing morbidity, mortality, and time of excretion, but few studies have evaluated in a systematic manner the value of antimicrobials for the management of EPEC infection in children. ${ }^{161,162}$
ETEC has been reported to be the most important pathogen responsible in traveler's diarrhea.

EAEC also plays an important role in traveler's diarrhea. Pathogen- and geographic-based approaches to traveler's diarrhea treatment should be encouraged. Fluoroquinolones and nonabsorbable rifaximin are the drugs of choice for travelers to high-risk areas in which E. coli is the predominant etiologic agent (Latin America, the Caribbean [Haiti and the Dominican Republic], and Africa), leaving azithromycin for travelers to South and Southeast Asia as well as patients with febrile dysenteric illnesses acquired in any region. ${ }^{163}$

Antibiotic therapy for STEC is complicated. The growth of $\mathrm{O} 157: \mathrm{H7}$ in the intestinal tract leads to diarrhea, and patients would presumably benefit if antibiotic treatment eliminated the bacteria. However, systemic dissemination of Shiga toxin type 2 produced by the bacteria in the intestinal tract can lead to life-threatening complications, including neurological damage and HUS. Antibiotic treatments that induce the phage lytic cycle, resulting in increased Shiga toxin production, could lead to more serious disease. Recent studies suggest that normal flora can have a profound impact on Shiga toxin production. Subinhibitory levels of antibiotics that target DNA synthesis, including ciprofloxacin and sulfamethoxazole-trimethoprim, increased Shiga toxin production, while antibiotics that target the cell wall, transcription, or translation did not. So ciprofloxacin and sulfamethoxazole-trimethoprim are not appropriate for treatment of O157:H7. In contrast, azithromycin significantly reduced Shiga toxin levels, even when relatively high levels of O157:H7 were recovered. ${ }^{164}$ Moreover, the eradication rate reported in STEC O104:H4 infections is $86 \%$. Azithromycin might be considered a potentially effective and safe antibiotic, and may be used safely for decolonization of STEC O104:H4 long-term carriage. ${ }^{165}$ Numerous outbreaks, as well as sporadic cases of STEC infections and HUS, have been documented worldwide. There are numerous reports on STEC O157:H7 as the most common serotype associated with HUS, especially in children. Several reports on non-O157 STEC underline their potential to cause sporadic disease as well as epidemics. During 2011, there was a large outbreak in Northern Germany, with a satellite outbreak in Western France caused by an EAEC of serotype O104:H4 expressing a phage-encoded Shiga toxin 2: clinicians were confronted with a large number of mainly adult patients with HUS associated with severe hemolysis and neurological complications. ${ }^{166}$ Medical centers used varying therapeutic regimens, including plasmapheresis, glucocorticoids, and the 
anti-C5 monoclonal antibody eculizumab, but currently there is no effective prophylaxis or treatment available for STEC infections and HUS. ${ }^{166}$ The probiotic Escherichia coli strain Nissle 1917 (EcN) seemed to have very efficient antagonistic activity on the EHEC strains of serotype O104:H4 and O157:H7, with reduced growth of pathogens. ${ }^{167}$

The 2011 outbreak strains perfectly showed the genome plasticity and evolution of $E$. coli as a result of horizontal gene transfer. These strains combine the virulence mechanisms of two pathotypes (EAEC and EHEC), leading to an improved ability to adhere to and infect host cells. Furthermore, the acquisition of mechanisms mediating increased antibiotic resistance hampered patient treatment and recovery. These strains have conserved most of the virulence factors of an EAEC strain, but several mobile genetic elements were responsible for the acquisition of new functions involved in high-frequency recombination, mobilization, and transfer of genes. Despite the alternative mechanisms that have evolved to colonize and adapt to new niches, $E$. coli strains have maintained a core genome sequence, and therefore share several components that could be useful targets for a universal vaccine against E. coli. Considering the increasing antibiotic resistance present among $E$. coli strains, which is derived from an uncontrolled use of antibiotics, vaccination is the most promising approach to control disease. ${ }^{168}$

Helicobacter pylori is a leading cause of chronic gastritis, peptic ulcers, nonulcer dyspepsia, gastric adenocarcinoma, and mucosa-associated lymphoid tissue lymphoma. Eradication of the pathogen has a failure rate of more than $30 \%$ in pediatric patients, particularly because of poor compliance, antibiotic resistance, and occurrence of side effects. ${ }^{169}$ Treatment regimens generally include a proton-pump inhibitor (lansoprazole, omeprazole, pantoprazole, rabeprazole, dexlansoprazole, or esomeprazole), which allows the tissues damaged by the infection to heal, and two antibiotics to reduce the risk of treatment failure and antibiotic resistance. Treatment requires several medications for 7-14 days. In pediatric patients, gastric mucosal lesion-caused $H$. pylori infection is a reversible process, and the eradication of this infection not only stops the activity of the inflammatory process but also restores the mucous membranes, reduces the incidence of recurrence of gastritis and peptic ulcer disease, and can lead to prevention of malignant disease in 70\%-80\% of cases. ${ }^{170}$ Adjuvant therapy with probiotics has been studied in recent years. ${ }^{169}$ In a recent randomized, placebo-controlled, double-blind study, children on $H$. pylori eradication therapy receiving seven strains of probiotic in addition to the standard triple regimen (omeprazole + amoxicillin + claritromicin or omeprazole + amoxycillin + furazolidon) were compared with patients on the same triple regimen receiving placebo. The findings reported a significant reduction in treatment complications and an improved therapeutic outcome: the rate of eradication was significantly higher, and children had a lower rate of nausea/vomiting and diarrhea during treatment. ${ }^{168}$ The long-term success of $H$. pylori eradication interventions for preventing gastric cancer, depends on the recurrence determinants (nonadherence and demographics) that are as important as a specific antibiotic regimen. ${ }^{171}$

Despite Plesiomonas shigelloides seeming to be a minor cause of bacterial enteritis, the pathogen has been implicated in gastroenteritis outbreaks in tropical regions and in cases of traveler's diarrhea. Antibacterials are used only in cases of severe and unresponsive infections: the most effective are ciprofloxacin and azythromycin, and partially trimethoprimsulfamethoxazole.

With Salmonella spp, antibiotics are initiated in cases of febrile diarrhea, especially in case of moderate to severe disease. The administration of azithromycin empirically for acute diarrhea, when indicated, could be appropriate. ${ }^{4,153}$ Consistent evidence from several clinical trials suggests that antibiotic treatment (ampicillin, amoxicillin, cefixime, azithromycin, cotrimoxazole) did not shorten the duration of diarrhea or lead to an earlier resolution of clinical symptoms. Intramuscular ampicillin protects children against relapse and reduces the carriage of Salmonella infection significantly better than placebo, oral ampicillin, or amoxicillin. ${ }^{4}$

Antibiotics are usually avoided in mild Shigella illness, because mild forms of Shigella dysentery are said to be self limiting, some Shigella strains are resistant to antibiotics, and their use may lead to increased resistance. If necessary, in severe cases, the choice of antibiotic to use as first line against Shigella dysentery should be governed by periodically updated local antibiotic sensitivity patterns of Shigella isolates. Other supportive and preventive measures recommended by the WHO should also be instituted along with antibiotics (eg, health education and hand-washing). Ciprofloxacin has been recommended by the WHO as the drug of choice for all patients with bloody diarrhea, irrespective of their ages. ${ }^{172}$ According to a recent Cochrane review, the authors did not find robust evidence to suggest that antibiotics of a particular class are better than those belonging to a different class. Trials report that at various periods of time, different antibiotics have been effective against isolates of Shigella dysentery in different parts of the world. These are ampicillin, cotrimoxazole, nalidixic acid, fluoroquinolones 
like ciprofloxacin, pivmecillinam, ceftriaxone, and azithromycin. However, limited data from a subgroup of studies suggest that a fluoroquinolone (ciprofloxacin) would be more effective than a beta-lactam (ampicillin) in reducing diarrhea among adults, and that beta-lactams would be more effective than fluoroquinolones in reducing diarrhea among children with proven Shigella dysentery. Emerging drug resistance to ciprofloxacin and second-line drugs such as pivmecillinam, ceftriaxone, and azithromycin is increasingly being reported in many parts of the world, as is multiple-drug resistance. ${ }^{173,174}$ In India, for example, several Shigella strains (S. flexneri, S. dysenteriae, S. boydii, and S. sonnei) isolated from children $\leq 15$ years of age are resistant to ampicillin, cotrimoxazole, ciprofloxacin, and nalidixic acid. Alternatives include ceftriaxone and azithromycin, but ceftriaxone is an injectable drug and azithromycin has limited therapeutic benefit, as organisms easily develop resistance to it. ${ }^{175}$ It has been noted that all Shigella spp utilize a type III secretion system to translocate bacterial proteins - invasins IpaA-D and IpgD - into host eukaryotic cells to initiate infection. Because they are common to all virulent Shigella spp, they seem to be ideal candidate antigens for a subunit-based broad-spectrum protective vaccine for prevention of shigellosis. ${ }^{176}$

Vibrio cholerae strains from endemic outbreaks within the last decade revealed patterns of antibiotic resistance to ampicillin, tetracycline, and trimethoprim correlated with widespread therapeutic and prophylactic administration of antibiotics. ${ }^{177}$ Treating severe cases of cholera with antibiotics is important, but the continuing spread of resistance to the most important therapeutic agents is a matter of concern, as some strains have either intermediate resistance or are resistant to ceftriaxone, ciprofloxacin, and tetracycline. ${ }^{178}$

The most common clinical manifestation of a Yersinia enterocolitica infection is a self-limited gastroenteritis that resolved spontaneously within 2 weeks. ${ }^{179} Y$. enterocolitica usually shows in vitro susceptibility to aminoglycosides, chloramphenicol, doxycycline, cotrimoxazole, third-generation cephalosporins, carabapenems, and fluoroquinolones. ${ }^{180}$ Recently, in a case-control study conducted among children aged less than 12 years, it was found that $Y$. enterocolitica is generally susceptible to meropenem $(100 \%)$, ceftriaxone (94\%), and ciprofloxacin (94\%), followed by ceftazidime $(88 \%)$ and amikacin $(81 \%)$. Almost all Y. enterocolitica was resistant to ampicillin. ${ }^{57}$

\section{Fungal}

Fungal infections of the gastrointestinal tract are not common in children, especially in immunocompetent ones.
In the neonatal period, Candida infections frequently develop into systemic forms. ${ }^{82}$ Fluconazole prophylaxis in infants $<1000 \mathrm{~g}$ ( $3 \mathrm{mg} / \mathrm{kg}$ twice a week), while intravenous access is required, appears to be safe and effective in preventing invasive Candida infections with or without diarrhea, while attenuating the emergence of fungal resistance. ${ }^{88,181}$ New echinocandines - anidulafungin, caspofungin, and micafungin, recently introduced - seem to have some advantages over fluconazole and amphotericin B, as they better meet the needs of pediatric patients, neonates, and in particular preterm infants with invasive candidiasis and/or diarrhea from Candida spp infection. Micafungin, a dose-dependent candidacidal agent with excellent in vitro efficacy against most Candida spp, including species resistant to amphotericin B, is approved for the treatment of invasive candidiasis in children, including preterm infants aged less than 3 months. Efficacy and safety were demonstrated in comparison with liposomal amphotericin B and fluconazole. The most appropriate dose in children weighing less than $40 \mathrm{~kg}$ is $2 \mathrm{mg} / \mathrm{kg} /$ day in the treatment of invasive candidiasis and or gastroenteritis and $1 \mathrm{mg} / \mathrm{kg}$ /day as prophylaxis. In premature infants, the most appropriate doses to achieve appropriate levels in the brain parenchyma are $7 \mathrm{mg} / \mathrm{kg}$ /day in infants weighing more than $1,000 \mathrm{~g}$ and $10 \mathrm{mg} / \mathrm{kg} /$ day in those weighing less than $1,000 \mathrm{~g}$, respectively. Micafungin has few drug-drug interactions and an acceptable safety profile thus providing a promising drug in the prophylactic and therapeutic management of invasive candidiasis. Micafungin has few drug-drug interactions, and an acceptable safety profile. ${ }^{182-184}$ Data from randomized trials conducted in pediatric and adult patients showed through a subgroup analysis that both caspofungin and micafungin are effective and well tolerated also in neonates. ${ }^{185,186}$

\section{Parasitic - protozoan}

The major causes of diarrhea worldwide in children are Cryptosporidium parvum, Giardia lamblia, and Entamoeba histolytica: "the neglected parasitic disease."

Cryptosporidium is a diarrheagenic protozoan pathogen for children, and immunosuppressed individuals are disproportionately affected. Until a few years ago, the most commonly used treatments, only partially effective, were paromomycin and azithromycin. Recent investigations have focused on nitazoxanide, as it significantly shortens the duration of diarrhea and decreases mortality in malnourished children. Nitazoxanide is not effective without an appropriate immune response, as in AIDS patients. ${ }^{187,188}$

Giardia lamblia is a diarrheagenic protozoan pathogen most commonly treated with metronidazole (MTZ) or tinidazole 
but failures occur in 10\%-20\% of cases. Albendazole may be of similar effectiveness to metronidazole, may have fewer side effects, and has the advantage of a simplified regimen. Nitazoxanide is a viable therapeutic option as an effective alternative to MTZ in reducing the duration of diarrhea. ${ }^{61,188,189}$ Auranofin, a gold complex classified by the WHO as an antirheumatic agent, has been revealed to be active against multiple MTZ-resistant strains blocking a critical enzyme involved in maintaining normal protein function. These results indicate that auranofin could be developed as an antigiardial drug, particularly against MTZ-resistant strains. ${ }^{190}$

Entamoeba histolytica amebiasis is the fourth-leading cause of death and the third-leading cause of morbidity due to protozoan infections worldwide. In children, effective drugs for diarrhea are MTZ and other nitroimidazoles. However, eradication of $E$. histolytica infection after completion of MTZ requires additional therapy with luminal amebicides, such as paramomycin. Nitazoxanide is a recent therapeutic advance, due to its action against luminal and invasive parasite forms. ${ }^{191}$ Nitazoxanide-treated patients had statistically shorter durations of diarrheal illness. Auranofin could represent a promising therapy for amebiasis. ${ }^{187}$

\section{Parasitic - helminths nematodes}

Strongyloides stercoralis and Trichuris trichiura are causes of diarrhea.

Strongyloides stercoralis can penetrate host skin and parasitize human intestines, leading to burning pain, tissue damage, ulcers, edema and obstruction of the intestinal tract, and diarrhea, as well as loss of peristaltic contractions. Ivermectin is the first-choice therapy because of its higher tolerance, and albendazole is the second-choice therapy. ${ }^{61,192}$

Trichuris trichiura is chiefly a tropical infection, and children are especially vulnerable to infection due to their high exposure risk. Light infestations ( $<100$ worms) are frequently asymptomatic, but heavy infestations may cause mechanical or inflammatory damage to the mucosa, abdominal pain, profuse or chronic diarrhea, and bloody diarrhea. Mebendazole seems to be the first-choice therapy and albendazole the second-choice therapy, while nitazoxanide shows no effect. An albendazole and nitazoxanide-albendazole combination showed only a minimal effect. There is a need to develop new anthelmintics against trichuriasis. ${ }^{193}$

\section{Conclusion}

AGE remains a major problem in children and still represents one of the leading causes of illness costs and of deaths, as an estimated 2.5 million gastroenteritis deaths occur each year in children less than 5 years of age throughout the world, especially in resource-constrained countries. In rich countries, transmission occurs much more frequently from contaminated food compared to direct person-to-person contact, except for enteric viruses, which can also be transmitted by aerosol formation after vomiting. Most cases of AGE in children are viral, self-limited, and need only supportive treatment. Rehydration (oral or intravenous) with an appropriate fluid-and-electrolyte balance, with close attention to nutrition, remains central to therapy: this may turn into an additional benefit in limiting hospitalizations.

Intestinal infections often require drugs such as antiemetics, antidiarrheal agents, and probiotics that may deeply change the impact, severity, and duration of acute diarrhea. In cases of severe infectious diarrhea with a prolonged course, signs of inflammation, bloody stool, immunosuppression, and comorbidity, and in suspected outbreaks, fecal microbial analysis, should always be performed, and a specific therapy should be considered if indicated to shorten the clinical course, eradicate causative organisms, reduce transmission, and prevent invasive complications. Selection of antibacterials to use in acute bacterial gastroenteritis is based on clinical diagnosis of the likely pathogen and on definitive laboratory results. Based on epidemiological data and after collecting organic materials for etiological diagnosis (often a single fecal sample studied for etiologic agents is the customary way to make an etiologic diagnosis), an initial empiric therapy may be appropriate in case of a severe illness, particularly in infancy and the immunocompromised. In case of suspected EHEC serotype 0157 and EAEC serotype O104:H4 (but also of Shigella dysenteriae serotype 1 ), as it is estimated that $5 \%-8 \%$ of infected individuals will develop HUS following STEC infection with $E$. coli O157:H7 the most commonly involved serotype, antibiotics should be prescribed according to more recent guidelines. Moreover, a major concern is the emergence of antibacterialresistant strains due to the widespread use of antibacterial agents: a continuous monitoring of antibiotic resistance in diarrhea-related bacterial pathogens is recommended. The benefits and risks of adverse drug reactions should be weighed before prescribing any kind of drug.

\section{Disclosure}

The authors report no conflicts of interest in this work.

\section{References}

1. Pieścik-Lech M, Shamir R, Guarino A, Szajewska H. Review article: the management of acute gastroenteritis in children. Aliment Pharmacol Ther. 2013;37:289-303. 
2. Guarino A, Dupont C, Gorelov AV, et al. The management of acute diarrhea in children in developed and developing areas: from evidence base to clinical practice. Expert Opin Pharmacother. 2012;13:17-26.

3. World Health Organization. Diarrhoea. Available from: http://www. who.int/topics/diarrhoea/en. Accessed April 7, 2013.

4. National Collaborating Centre for Women's and Children's Health. Diarrhea and Vomiting Caused by Gastroenteritis: Diagnosis, Assessment and Management in Children Younger Than 5 Years. London: RCOG Press; 2009. Available from: http://www.nice.org.uk/nicemedia/ pdf/CG84FullGuideline.pdf. Accessed March 31, 2012.

5. Chow CM, Leung AK, Hon KL. Acute gastroenteritis: from guidelines to real life. Clin Exp Gastroenterol. 2010;3:97-112.

6. Guarino A, Albano F, Ashkenazi S, et al. European Society for Paediatric Gastroenterology, Hepatology, and Nutrition/European Society for Paediatric Infectious Diseases evidence-based guidelines for the management of acute gastroenteritis in children in Europe. $J$ Pediatr Gastroenterol Nutr. 2008;46 Suppl 2:S81-S122.

7. Forster J, Guarino A, Parez N, et al. Hospital-based surveillance to estimate the burden of rotavirus gastroenteritis among European children younger than 5 years of age. Pediatrics. 2009;123:e393-e400.

8. Albano F, Bruzzese E, Bella A, et al. Rotavirus and not age determines gastroenteritis severity in children: a hospital-based study. Eur J Pediatr. 2007;166:241-247.

9. Parashar UD, Gibson CJ, Bresee JS, Glass RI. Rotavirus and severe childhood diarrhea. Emerg Infect Dis. 2006;12:304-306.

10. De Rougemont A, Kaplon J, Pillet S, et al. Molecular and clinical characterization of rotavirus from diarrheal infants admitted to pediatric emergency units in France. Pediatr Infect Dis J. 2011;30:118-124.

11. Palumbo E, Branchi M, Malorgio C, et al. Diarrhea in children: etiology and clinical aspects. Minerva Pediatr. 2010;62 347-351.

12. Kinnula S, Buettcher M, Tapiainen T, et al. Hospital-associated infections in children: a prospective post-discharge follow-up survey in three different paediatric hospitals. J Hosp Infect. 2012;80:17-24

13. Wittenberg DF. Management guidelines for acute infective diarrhoea/ gastroenteritis in infants. S Afr Med J. 2012;102:104-107.

14. Ganguli K, Walker WA. Probiotics in the prevention of necrotizing enterocolitis. J Clin Gastroenterol. 2011;45 Suppl:S133-S138.

15. Vandenplas Y, Veereman-Wauters G, et al. Probiotics and prebiotics in prevention and treatment of diseases in infants and children. Pediatr (Rio J). 2011;87(4):292-300. English, Portuguese.

16. Kligler B, Hanaway P, Cohrssen A. Probiotics in children. Pediatr Clin North Am. 2007;54:949-967.

17. Quigley MA, Kelly YJ, Sacker A. Breast-feeding and hospitalization for diarrhoeal and respiratory infection in the United Kingdom Millenium Cohort Study. Pediatrics. 2007;119:e837-e842.

18. Quigley MA, Cumberland P, Cowden JM, et al. How protective is breast-feeding against diarrheal disease in infants in 1990s England? A case-control study. Arch Dis Child. 2006;91:245-250.

19. Satyanarayana L, Kumar S. Water supplementation in exclusively breastfed infants during summer in the tropics. Lancet. 1991;337: 929-933.

20. Williams HG. And not a drop to drink - why water is harmful for newborns. Breastfeed Rev. 2006;14:5-9.

21. Mansour AM, Abd Elkhalek R, et al. Burden of Aeromonas hydrophilaassociated diarrhea among children younger than 2 years in rural Egyptian community. J Infect Dev Ctries. 2012;6:842-846.

22. Bhutta ZA. Acute gastroenteritis in children. In Kliegman RM, Behrman RE, Jenson HB, Stanton BF, editors. Nelson's Textbook of Pediatrics, 18th ed. Philadelphia: Saunders; 2007.

23. Mortensen NP, Schiellerup P, Boisen N, et al. The role of Campylobacter jejuni cytolethal distending toxin in gastroenteritis: toxin detection, antibody production, and clinical outcome. APMIS. 2011;119: 626-634.

24. McGrogan A, Madle GC, Seaman HE, de Vries CS. The epidemiology of Guillain-Barré syndrome worldwide. A systematic literature review. Neuroepidemiology. 2009;32:150-163.
25. Jacobs BC, Van Belkum A, Endtz HP. Guillain-Barré syndrome and Campylobacter infection. In: Nachamkin I, Szymanski CM, Blaser MJ, editors. Campylobacter, 3rd ed. Washington: American Society for Microbiology; 1998:245-261.

26. Poropatich KO, Walker CL, Black RE. Quantifying the association between Campylobacter infection and Guillain-Barré syndrome: a systematic review. J Health Popul Nutr. 2010;28:545-552.

27. Alam S, Mushtaq M. Antibiotic associated diarrhea in children. Indian Pediatr. 2009;46:491-496.

28. Zilberberg MD, Shorr AF, Kollef MH. Increase in Clostridium difficilerelated hospitalizations among infants in the United States, 2000-2005. Pediatr Infect Dis J. 2008;27:1111-1113.

29. Kim J, Smathers SA, Prasad P, Leckerman KH, Coffin S, Zaoutis T. Epidemiological features of Clostridium difficile-associated disease among inpatients at children's hospitals in the United States, 2001-2006. Pediatrics. 2008;122:1266-1270.

30. Luna RA, Boyanton BL Jr, Mehta S, et al. Rapid stool-based diagnosis of Clostridium difficile infection by real-time PCR in a children's hospital. J Clin Microbiol. 2011;49:851-857.

31. Baron S, editor. Medical Microbiology, 4th ed. Galveston (TX): University of Texas Medical Branch at Galveston; 1996. Available from: http://www. ncbi.nlm.nih.gov/books/NBK7627. Accessed April 7, 2013.

32. Chang JY, Shin SM, Chun J, Lee JH, Seo JK. Pyrosequencing-based molecular monitoring of the intestinal bacterial colonization in preterm infants. J Pediatr Gastroenterol Nutr. 2011;53:512-519.

33. Käppeli U, Hächler H, Giezendanner N, Beutin L, Stephan R. Human infections with non-O157 Shiga toxin-producing Escherichia coli, Switzerland, 2000-2009. Emerg Infect Dis. 2011;17:180-185.

34. Karmali MA, Steele BT, Petric M, Lim C. Sporadic cases of haemolyticuraemic syndrome associated with faecal cytotoxin and cytotoxinproducing Escherichia coli in stools. Lancet. 1983;1:619-620.

35. Riley LW, Remis RS, Helgerson SD, et al. Hemorrhagic colitis associated with a rare Escherichia coli serotype. N Engl J Med. 1983;308: 681-685.

36. Peacock E, Jacob VW, Fallone SM. Escherichia coli O157:H7: etiology, clinical features, complications, and treatment. Nephrol Nurs J. 2001;28:547-550.

37. Clarke SC. Diarrhoeagenic Escherichia coli - an emerging problem? Diagn Microbiol Infect Dis. 2001;41:93-98.

38. Vally H, Hall G, Dyda A, et al. Epidemiology of Shiga toxin producing Escherichia coli in Australia, 2000-2010. BMC Public Health. 2012;12:63.

39. Bettleheim K. The non-O157 Shiga toxigenic (verotocytotoxigenic) Escherichia coli: under-rated pathogens. Crit Rev Microbiol. 2007;33:67-87.

40. Griffin PM, Tauxe RV. The epidemiology of infections caused by Escherichia coli $\mathrm{O} 157: \mathrm{H7}$, other enterohemorrhagic $E$. coli, and the associated hemolytic uremic syndrome. Epidemiol Rev. 1991;13:60-98.

41. [No authors listed]. The community summary report on trends and sources of zoonoses and zoonotic agents in the European Union in 2008. EFSA J. 2010;10:1496.

42. Gould LH, Bopp C, Strockbine N, et al. Recommendations for diagnosis of shiga toxin-producing Escherichia coli infections by clinical laboratories. MMWR Recomm Rep. 2009;58:1-14.

43. Perry S, Sanchez L, Yang S, et al. Helicobacter pylori and risk of gastroenteritis. J Infect Dis. 2004;190: 303-310.

44. Sullivan PB, Thomas JE, Wight DG, et al. Helicobacter pylori in Gambian children with chronic diarrhoea and malnutrition. Arch Dis Child. 1990;65:189-191.

45. Clemens J, Albert MJ, Rao M, et al. Impact of infection by Helicobacter pylori on the risk and severity of endemic cholera. J Infect Dis. 1995; 171:1653-1656.

46. Bhan MK, Bahl R, Sazawal S, et al. Association between Helicobacter pylori infection and increased risk of typhoid fever. J Infect Dis. 2002; 186:1857-1860.

47. Passaro DJ, Taylor DN, Meza R, et al. Acute Helicobacter pylori infection is followed by an increase in diarrheal disease among Peruvian children. Pediatrics. 2001;108:E87. 
48. Isenbarger DW, Bodhidatta L, Hoge CW, et al. Prospective study of the incidence of diarrheal disease and Helicobacter pylori infection among children in an orphanage in Thailand. Am J Trop Med Hyg. 1998;59:796-800.

49. Pütsep K, Brändén CI, Boman HG, Normark S. Antibacterial peptide from H. pylori. Nature. 1999;398:671-672.

50. Rothenbacher D, Blaser MJ, Bode G, Brenner H. Inverse relationship between gastric colonization of Helicobacter pylori and diarrheal illnesses in children: results of a population-based cross-sectional study. J Infect Dis. 2000;182:1446-1449.

51. Sachs G, Weeks DL, Melchers K, Scott DR. The gastric biology of Helicobacter pylori. Annu Rev Physiol. 2003;65:349-369.

52. Dore MP, Fanciulli G, Tomasi PA, et al. Gastrointestinal symptoms and Helicobacter pylori infection in school-age children residing in Porto Torres, Sardinia, Italy. Helicobacter. 2012;17:369-373.

53. Kamga HL, Assob JC, Nsagha DS, et al. Epidemiological studies on proteeae isolates from clinical specimens in the Laquintinie Hospital in Douala, Cameroon. Afr J Clin Exper Microbiol. 2012;13:112-120.

54. Crivaro V, Di Popolo A, Caprio A, et al. Pseudomonas aeruginosa in a neonatal intensive care unit: molecular epidemiology and infection control measures. BMC Infect Dis. 2009;9:70.

55. Caramia G, Ruffini E, Salvatori P. Infectious gastroenteritis. From: Neonatal Infectious Diseases Study Group of the Italian Society of Neonatology. Manual of Neonatal Infectious Diseases. Milan: Biomedia. 2009.

56. Wu T, Grassel C, Levine MM, et al. Live attenuated Shigella dysenteriae type 1 vaccine strains overexpressing shiga toxin B subunit. Infect Immun. 2011;79:4912-4922.

57. El Qouqa IA, El Jarou MA, Samaha AS, et al. Yersinia enterocolitica infection among children aged less than 12 years: a case-control study. Int J Infect Dis. 2011;15:e48-e53.

58. Batzilla J, Heesemann J, Rakin A. The pathogenic potential of Yersinia enterocolitica 1A. Int J Med Microbiol. 2011;301:556-561.

59. Dennehy PH. Viral gastroenteritis in children. Pediatr Infect Dis J. 2011;30:63-64

60. Pawlowski SW, Warren CA, Guerrant R. Diagnosis and treatment of acute or persistent diarrhea. Gastroenterology. 2009;136: 1874-1886.

61. Caramia G, Ruffini E, Fanos V. Infections and Pediatric Pharmacotheray, 4th ed. Milan: Biomedia; 2007.

62. Goodgame RW. Viral infections of the gastrointestinal tract. Curr Gastroenterol Rep. 1999;1:292-300.

63. Rimoldi SG, Stefani F, Pagani C, et al. Epidemiological and clinical characteristics of pediatric gastroenteritis associated with new viral agents. Arch Virol. 2011;156:1583-1589.

64. Tokarz R, Firth C, Madhi SA, et al. Worldwide emergence of multiple clades of enterovirus 68. J Gen Virol. 2012;93:1952-1958.

65. Chitambar S, Gopalkrishna V, Chhabra P, et al. Diversity in the enteric viruses detected in outbreaks of gastroenteritis from Mumbai, Western India. Int J Environ Res Public Health. 2012;9:895-815.

66. Li J, Lin C, Qu M, et al. Excretion of enterovirus 71 in persons infected with hand, foot and mouth disease. Virol J. 2013;10:31.

67. Wildenbeest JG, van den Broek PJ, Benschop KS, et al. Pleconaril revisited: clinical course of chronic enteroviral meningoencephalitis after treatment correlates with in vitro susceptibility. Antivir Ther. 2012;17:459-466.

68. Zhu FC, Liang ZL, Li XL, et al. Immunogenicity and safety of an enterovirus 71 vaccine in healthy Chinese children and infants: a randomised, double-blind, placebo-controlled phase 2 clinical trial. Lancet. Epub January 23, 2013.

69. Proenca-Modena JL, Martinez M, Amarilla AA, et al. Viral load of human bocavirus-1 in stools from children with viral diarrhoea in Paraguay. Epidemiol Infect. Epub February 21, 2013.

70. Risku M, Lappalainen S, Räsänen S, Vesikari T. Detection of human coronaviruses in children with acute gastroenteritis. J Clin Virol. 2010;48:27-30.
71. Iritani N, Seto Y, Kubo H, et al. Prevalence of Norwalk-like virus infections in cases of viral gastroenteritis among children in Osaka City, Japan. J Clin Microbiol. 2003;41:1756-1759.

72. Medici MC, Martinelli M, Arcangeletti MC, et al. Epidemiological aspects of human rotavirus infection in children hospitalized with acute gastroenteritis in an area of northern Italy. Acta Biomed. 2004; 75:100-106

73. Moreno-Espinosa S, Farkas T, Jiang X. Human caliciviruses and pediatric gastroenteritis. Semin Pediatr Infect Dis. 2004;15:237-245.

74. Hansman GS, Saito H, Shibata C, et al. Outbreak of gastroenteritis due to sapovirus. J Clin Microbiol. 2007;45:1347-1349.

75. Oka T, Mori K, Iritani N, et al. Human sapovirus classification based on complete capsid nucleotide sequences. Arch Virol. 2012;157: 349-352.

76. Burián Z, Szabó H, Székely G, et al. Detection and follow-up of torque teno midi virus ("small anelloviruses") in nasopharyngeal aspirates and three other human body fluids in children. Arch Virol. 2011;156: $1537-1541$

77. Jelcic I, Hotz-Wagenblatt A, Hunziker A, et al. Isolation of multiple TT virus genotypes from spleen biopsy tissue from a Hodgkin's disease patient: genome reorganization and diversity in the hypervariable region. J Virol. 2004;78:7498-7507.

78. Peng YH, Nishizawa T, Takahashi M, et al. Analysis of the entire genomes of thirteen TT virus variants classifiable into the fourth and fifth genetic groups, isolated from viremic infants. Arch Virol. 2002;147:21-41.

79. Kekarainen T, Segalés J. Torque teno virus infection in the pig and its potential role as a model of human infection. Vet J. 2009;180: 163-168.

80. Friedman M, Ramsay DB, Borum ML. An unusual case report of small bowel Candida overgrowth as a cause of diarrhea and review of the literature. Dig Dis Sci. 2007;52:679-680.

81. Bond S, Stewart DL, Bendon RW. Invasive Candida enteritis of the newborn. J Pediatr Surg. 2000;35:1496-1498.

82. Ali GY, Algohary EH, Rashed KA, Alm Kh. Prevalence of Candida colonization in preterm newborns and VLBW in neonatal intensive care unit: role of maternal colonization as a risk factor in transmission of disease. J Matern Fetal Neonatal Med. 2012;25: 789-795.

83. Manzoni P, Mostert M, Jacqz-Aigrain E, S Fa Candida colonization in the nursery. J Pediatr (Rio J). 2012;88:187-190.

84. Zaoutis T, Walsh TJ. Antifungal therapy for neonatal candidiasis. Curr Opin Infect Dis. 2007;20:592-597.

85. Benjamin DK Jr, Smith PB, Arrieta A, et al. Safety and pharmacokinetics of repeat-dose micafungin in young infants. Clin Pharmacol Ther. 2010;87:93-99.

86. Allen U, Richardson S, McGuire W, et al. Pediatric antifungal therapy. Part II: neonatal infections. Minerva Pediatr. 2010;62:71-78.

87. Hsieh E, Smith PB, Jacqz-Aigrain E, et al. Neonatal fungal infections: when to treat? Early Hum Dev. 2012;88 Suppl 2:S6-S10.

88. Kaufman DA. "Getting to zero": preventing invasive Candida infections and eliminating infection-related mortality and morbidity in extremely preterm infants. Early Hum Dev. 2012;88 Suppl 2:S45-S49.

89. Leibovitz E. Strategies for the prevention of neonatal candidiasis. Pediatr Neonatol. 2012;53:83-89.

90. Liévin-Le Moal V. Dysfunctions at human intestinal barrier by water-borne protozoan parasites: lessons from cultured human fully-differentiated colon cancer cell lines. Cell Microbiol. Epub February 26, 2013.

91. Elgun G, Koltas IS. Investigation of Cryptosporidium spp. antigen by ELISA method in stool specimens obtained from patients with diarrhea. Parasitol Res. 2011;108:395-397.

92. Ali SA, Hill DR. Giardia intestinalis. Curr Opin Infect Dis. 2003;16: 453-460.

93. Nkrumah B, Nguah SB. Giardia lamblia: a major parasitic cause of childhood diarrhoea in patients attending a district hospital in Ghana. Parasit Vectors. 2011;4:163. 
94. Samie A, Obi LC, Bessong PO, Stroup S, Houpt E, Guerrant RL. Prevalence and species distribution of E. histolytica and E. dispar in the Venda region, Limpopo, South Africa. Am J Trop Med Hyg. 2006;75: 565-571.

95. Haque R, Mondal D, Karim A, et al. Prospective case-control study of the association between common enteric protozoal parasites and diarrhea in Bangladesh. Clin Infect Dis. 2009;48:1191-1197.

96. Norsarwany M, Abdelrahman Z, Rahmah N, et al. Symptomatic chronic strongyloidiasis in children following treatment for solid organ malignancies: case reports and literature review. Trop Biomed. 2012;29:479-488.

97. Keske LA, Letizia M. Clostridium difficile infection: essential information for nurses. Medsurg Nurs. 2010;19:329-332.

98. Pereira LA, Raboni SM, Nogueira MB, et al. Rotavirus infection in a tertiary hospital: laboratory diagnosis and impact of immunization on pediatric hospitalization. Braz J Infect Dis. 2011;15:215-219.

99. Shima A, Hinenoya A, Asakura M, et al. Prevalence of Providencia strains among children with diarrhea in Japan. Jpn J Infect Dis. 2012;65:545-547.

100. Kagambèga A, Martikainen O, Siitonen A, et al. Prevalence of diarrheagenic Escherichia coli virulence genes in the feces of slaughtered cattle, chickens, and pigs in Burkina Faso. Microbiologyopen. 2012;1:276-284.

101. Nakhjavani FA, Emaneini M, Hosseini H, et al. Molecular analysis of typical and atypical enteropathogenic Escherichia coli (EPEC) isolated from children with diarrhoea. J Med Microbiol. 2013;62: 191-195.

102. Health Protection Agency. Guidance on infection control in schools and other childcare settings. 2010. Available from: http://www.hpa org.uk/webc/HPAwebFile/HPAweb_C/1194947358374. Accessed April 8, 2013.

103. PHLS Advisory Committee on Gastrointestinal Infections. Preventing person-to-person spread following gastrointestinal infections: guidelines for public health physicians and environmental health officers. Commun Dis Public Health. 2004;7:362-384.

104. Patel M, Pedreira C, de Olivieria LH, et al. Association between pentavalent rotavirus vaccine and severe rotavirus diarrhoea among children in Nicaragua. JAMA. 2009;301:2243-2251.

105. Tate JE, Cortese MM, Payne DC, et al. Uptake, impact, and effectiveness of rotavirus vaccination in the United States: review of the first 3 years of postlicensure data. Pediatr Infect Dis J. 2011;30:S56-S60.

106. Munos MK, Walker CL, Black RE. The effect of rotavirus vaccine on diarrhea mortality. Int J Epidemiol. 2010;39:i56-i62.

107. Vesikari T, Van Damme P, Giaquinto C, et al. European Society for Paediatric Infectious Diseases/European Society for Paediatric Gastroenterology, Hepatology, and Nutrition evidence-based recommendations for rotavirus vaccination in Europe. $J$ Pediatr Gastroenterol Nutr. 2008;46:S38-S48.

108. Parashar UD, Alexander JP, Glass RI. Prevention of rotavirus gastroenteritis among infants and children. Recommendations of the Advisory Committee on Immunization Practices (ACIP). MMWR Recomm Rep. 2006;55:1-13.

109. Khin MU, Nyunt-Nyunt-Wai, et al. Effect on clinical outcome of breast feeding during acute diarrhoea. Br Med J (Clin Res Ed). 1985;290:587-589.

110. Casburn-Jones AC, Farthing MJG. Management of infectious diarrhoea. Gut. 2004;53:296-305.

111. Walker A. Breast milk as the gold standard for protective nutrients. J Pediatr. 2010;156:S3-S7.

112. Plenge-Bönig A, Soto-Ramírez N, Karmaus W, Petersen G, Davis S, Forster J. Breastfeeding protects against acute gastroenteritis due to rotavirus in infants. Eur J Pediatr. 2010;169:1471-1476.

113. Ladomenou F, Moschandreas J, Kafatos A, Tselentis Y, Galanakis E. Protective effect of exclusive breastfeeding against infections during infancy: a prospective study. Arch Dis Child. 2010;95: 1004-1008.
114. Caramia G. Gastroenteric pathology and probiotics: from myth to scientific evidence. Current aspects. Minerva Gastroenterol Dietol. 2009;55:237-272.

115. Caramia G, Silvi S. Probiotics: from the ancient wisdom to the actual therapeutical and nutraceutical perspective. In: Malago JJ, Koninkx JFJG, Marinsek-Logar R. Probiotic Bacteria and Enteric Infections: Cytoprotection by Probiotic Bacteria. Heidelberg: Springer; 2011: 3-38.

116. Allen SJ, Martinez EG, Gregorio GV, Dans LF. Probiotics for treating acute infectious diarrhoea. Cochrane Database Syst Rev. 2010;11:CD003048.

117. Rojas MA, Lozano JM, Rojas MX, et al. Prophylactic probiotics to prevent death and nosocomial infection in preterm infants. Pediatrics. 2012;130:e1113-e1120.

118. World Health Organization. First Steps for Managing an Outbreak of Acute Diarrhea. Geneva: WHO; 2004. Available from: http://www. who.int/topics/cholera/publications/en/first_steps.pdf. Accessed April 8, 2013.

119. Ognio LS. Protocolo de Vigilancia Epidemiológica de Cólera. Lima: Oficina General de Epidemiologia, Ministério de Salud de Peru; 2006.

120. Murphy C, Hahn S, Volmink J. Reduced osmolarity oral rehydration solution for treating cholera. Cochrane Database Syst Rev. 2004;4:CD003754

121. Hirschhorn NJ, Kinzie JL, Sachar DB, et al. Decrease in net stool output in cholera during intestinal perfusion with glucose-containing solutions. N Engl J Med. 1968;279:176-181.

122. Pierce NF, Sack RB, Mitra RC, et al. Replacement of water and electrolyte losses in cholera by an oral glucose-electrolyte solution. Ann Intern Med. 1969;70:1173-1181.

123. MacKenzie A, Barnes G. Randomized controlled trial comparing oral and intravenous rehydration therapy in children with diarrhea. $B M J$. 1991;303:393-396

124. Hartling L, Bellemare S, Wiebe N, et al. Oral versus intravenous rehydration for treating dehydration due to gastroenteritis in children. Cochrane Database of Syst Rev. 2006;3: CD004390.

125. Caramia G, Pompilio A, Ciuccarelli F, et al. Dehydration and rehydration. State of the art and therapeutic interventions. Prog Nutr. 2003;5(4):299-313.

126. Ali SA, Hill DR. Giardia intestinalis. Curr Opin Infect Dis. 2003;16: 453-460.

127. Fabiani E, Catassi C, Vignini M, et al. La gastroenterite acuta: reidratazione, alimentazione e terapia al pronto soccorso. In: Tavola Rotonda. La Gastroenterite Acuta: Reidratazione, Alimentazione, Terapia; 2005.

128. Rautenberg TA, Zerwes U, Foerster D, Aultman R. Evaluating the cost utility of racecadotril for the treatment of acute watery diarrhea in children: the RAWD model. Clinicoecon Outcomes Res. 2012;4: 109-116.

129. Lehert P, Chéron G, Calatayud GA, et al. Racecadotril for childhood gastroenteritis: an individual patient data meta-analysis. Dig Liver Dis. 2011;43:707-713.

130. Salazar-Lindo E, Santisteban-Ponce J, Chea-Woo E, Gutierrez M. Racecadotril in the treatment of acute watery diarrhea in children. N Engl J Med. 2000;343:463-467.

131. Cézard JP, Duhamel JF, Meyer M, et al. Efficacy and tolerability of racecadotril in acute diarrhea in children. Gastroenterology. 2001;120: 799-805.

132. Sturm JJ, Pierzchala A, Simon HK, Hirsh DA. Ondansetron use in the pediatric emergency room for diagnoses other than acute gastroenteritis. Pediatr Emerg Care. 2012;28:247-250.

133. Fedorowicz Z, Jagannath VA, Carter B. Antiemetics for reducing vomiting related to acute gastroenteritis in children and adolescents. Cochrane Database Syst Rev. 2011;9:CD005506.

134. Freedman SB, Adler M, Seshadri R, Powell EC. Oral ondansetron for gastroenteritis in a pediatric emergency department. $N$ Engl J Med. 2006;354:1698-1705. 
135. Ramsook C, Sahagun-Carreon I, Kozinetz CA, Moro-Sutherland D. A randomized clinical trial comparing oral ondansetron with placebo in children with vomiting from acute gastroenteritis. Ann Emerg Med. 2002;39:397-403.

136. World Health Organization. Unedited Draft Report of the 17th Expert Committee on the Selection and Use of Essential Medicines. Geneva: WHO; 2009. Available from: http://www.who.int/selection_medicines/ committees/expert/17/WEBuneditedTRS_2009.pdf. Accessed April 8, 2013.

137. Prasad AS. Discovery of human zinc deficiency: 50 years later. JTrace Elem Med Biol. 2012;26:66-69.

138. Lazzerini M, Ronfani L. Oral zinc for treating diarrhoea in children. Cochrane Database Syst Rev. 2012;6:CD005436.

139. Kouame KS, Verga ME, Pittet A, et al. Zinc and diarrhea in children under 5 years: WHO recommendations implemented in Switzerland. Rev Med Suisse. 2012;8:1244-1247. French.

140. Allen SJ, Okoko B, Martinez E, et al. Probiotics for treating infectious diarrhoea. Cochrane Database Syst Rev. 2004;2:CD003048.

141. Szajewska H. Probiotics and prebiotics in pediatrics: where are we now? Turk J Pediatr. 2007;49:231-244.

142. Szajewska H, Skorka A, Dylag M. Meta-analysis: Saccharomyces boulardii for treating acute diarrhoea in children. Aliment Pharmacol Ther. 2007;25:257-264.

143. Francavilla R, Lionetti E, Castellaneta S, et al. Randomised clinical trial: Lactobacillus reuteri DSM 17938 vs placebo in children with acute diarrhoea - a double-blind study. Aliment Pharmacol Ther. 2012;36:363-369.

144. Hajela N, Nair GB, Abraham P, Ganguly NK. Health impact of probiotics - vision and opportunities. Gut Pathog. 2012;4:1

145. Guandalini S. Probiotics for children with diarrhea: an update. J Clin Gastroenterol. 2008;42 Suppl 2:S53-S57.

146. Lin YP, Thibodeaux CH, Peña JA, et al. Probiotic Lactobacillus reuteri suppress proinflammatory cytokines via c-Jun. Inflamm Bowel Dis. 2008; 14:1068-1083.

147. Thomas CM, Hong T, van Pijkeren JP, et al. Histamine derived from probiotic Lactobacillus reuteri suppresses TNF via modulation of PKA and ERK signaling. PLoS One. 2012;7: e31951.

148. Phavichitr N, Catto-Smith A. Acute gastroenteritis in children: what role for antibacterials? Paediatr Drugs. 2003;5:279-290.

149. Onwuezobe IA, Oshun PO, Odigwe CC. Antimicrobials for treating symptomatic non-typhoidal Salmonella infection. Cochrane Database Syst Rev. 2012;11:CD001167.

150. Pfeiffer ML, DuPont HL, Ochoa TJ. The patient presenting with acute dysentery - a systematic review. J Infect. 2012;64:374-386.

151. Maetz B, Abbou R, Andreoletti JB, Bruant-Rodier C. Infections following the application of leeches: two case reports and review of the literature. J Med Case Rep. 2012;6:364.

152. Wilmer A, Slater K, Yip J, et al. The role of leech water sampling in choice of prophylactic antibiotics in medical leech therapy. Microsurgery. Epub February 18, 2013.

153. Maragkoudakis S, Poulidaki SR, Papadomanolaki E, et al. Empiric antimicrobial therapy and infectious diarrhea. Do we need local guidelines? Eur J Intern Med. 2011;22:e60-e62.

154. Iovine NM. Resistance mechanisms in Campylobacter jejuni. Virulence. 2013;4:230-240.

155. Khalaf N, Crews JD, DuPont HL, Koo HL. Clostridium difficile: an emerging pathogen in children. Discov Med. 2012;14: 105-113.

156. Valerio M, Pedromingo M, Muñoz P, et al. Potential protective role of linezolid against Clostridium difficile infection. Int J Antimicrob Agents. 2012;39:414-419.

157. Whitman CB, Czosnowski QA. Fidaxomicin for the treatment of Clostridium difficile infections. Ann Pharmacother. 2012;46: 219-228.

158. Khanna S, Pardi DS. Clostridium difficile infection: new insights into management. Mayo Clin Proc. 2012;87:1106-1117.
159. Foglia G, Shah S, Luxemburger C, Pietrobon PJ. Clostridium difficile: development of a novel candidate vaccine. Vaccine. 2012;30: 4307-4309.

160. Al Jarousha AM, El Jarou MA, El Qouqa IA. Bacterial enteropathogens and risk factors associated with childhood diarrhea. Indian J Pediatr. 2011;78:165-170.

161. Behiry IK, Abada EA, Ahmed EA, Labeeb RS. Enteropathogenic Escherichia coli associated with diarrhea in children in Cairo, Egypt. ScientificWorldJournal. 2011;11:2613-2619.

162. Ochoa TJ, Contreras CA. Enteropathogenic Escherichia coli infection in children. Curr Opin Infect Dis. 2011;24:478-483.

163. De la Cabada Bauche J, Dupont HL. New developments in traveler's diarrhea. Gastroenterol Hepatol (N Y). 2011;7:88-95.

164. McGannon CM, Fuller CA, Weiss AA. Different classes of antibiotics differentially influence shiga toxin production. Antimicrob Agents Chemother. 2010;54:3790-3798.

165. Nitschke M, Sayk F, Härtel C, et al. Association between azithromycin therapy and duration of bacterial shedding among patients with Shiga toxin-producing enteroaggregative Escherichia coli O104:H4. JAMA. 2012;307:1046-1052.

166. Hauswaldt S, Nitschke M, Sayk F, et al. Lessons learned from outbreaks of Shiga toxin producing Escherichia coli. Curr Infect Dis Rep. 2013;15:4-9.

167. Rund SA, Rohde H, Sonnenborn U, Oelschlaeger TA. Antagonistic effects of probiotic Escherichia coli Nissle 1917 on EHEC strains of serotype O104:H4 and O157:H7. Int J Med Microbiol. 2013; 303:1-8

168. Moriel DG, Rosini R, Seib KL, et al. Escherichia coli: great diversity around a common core. MBio. 2012;3:e00118-e00112.

169. Ahmad K, Fatemeh F, Mehri N, Maryam S. Probiotics for the treatment of pediatric Helicobacter pylori infection: a randomized double blind clinical trial. Iran J Pediatr. 2013;23:79-84.

170. Brigic E, Hadzic D, Mladina N. Childhood and Coress model of carcinogenesis. Med Arh. 2012;66:375-377.

171. Morgan DR, Torres J, Sexton R, et al. Risk of recurrent Helicobacter pylori infection 1 year after initial eradication therapy in 7 Latin American communities. JAMA. 2013;309:578-586.

172. World Health Organization. Guidelines for the Control of Shigellosis, Including the Epidemics Which Were Caused by Shigella dysenteriae Type 1. Geneva: WHO; 2005.

173. Christopher PR, David KV, John SM, Sankarapandian V. Antibiotic therapy for Shigella dysentery. Cochrane Database Syst Rev. 2010;8: CD006784.

174. Von Seidlein L, Kim DR, Ali M,et al. A multi centre study of Shigella diarrhoea in six Asian countries: disease burden, clinical manifestations, and microbiology. PLoS Med. 2006;3:e353.

175. Mandal JVG, Emelda JSM, Parija SC. The recent trends of shigellosis: a JIPMER perspective. J Clin Diagn Res. 2012;6:1474-1477.

176. Martinez-Becerra FJ, Kissmann JM, Diaz-McNair J, et al. Broadly protective Shigella vaccine based on type III secretion apparatus proteins. Infect Immun. 2012;80:1222-1231.

177. Adagbada AO, Adesida SA, Nwaokorie FO, Niemogha MT, Coker AO. Cholera epidemiology in Nigeria: an overview. Pan Afr Med J. 2012;12:59.

178. Mandal J, Dinoop KP, Parija SC, et al. Increasing antimicrobial resistance of Vibrio cholerae OI biotype E1 tor strains isolated in a tertiary-care centre in India. J Health Popul Nutr. 2012;30:12-16.

179. Huovinen E, Sihvonen LM, Virtanen MJ, Symptoms and sources of Yersinia enterocolitica-infection: a case-control study. BMC Infect Dis. 2010;10:122.

180. Carniel E, Hinnebush BJ. Yersinia: Molecular and Cellular Biology. Wymondham, UK: Horizon Bioscience; 2004.

181. Manzoni P, Mostert M, Latino MA, et al. Clinical characteristics and response to prophylactic fluconazole of preterm VLBW neonates with baseline and acquired fungal colonisation in NICU: data from a multicentre RCT. Early Hum Dev. 2012;88 Suppl 2:S60-S64. 
182. Ramos Amador JT, Prieto Tato L, Guillén Martín S. Why might micafungin be the drug of choice in pediatric patients? Enferm Infecc Microbiol Clin. 2011;29 Suppl 2:23-28.

183. Hope WW, Smith PB, Arrieta A, et al. Population pharmacokinetics of micafungin in neonates and young infants. Antimicrob Agents Chemother. 2010;54:2633-2637.

184. Montejo M, Quindòs G. Scientific evidence supporting the use of micafungin in the treatment of invasive candidiasis. Enferm Infecc Microbiol Clin. 2011;29 Suppl 2:15-22.

185. Manzoni P, Benjamin DK, Franco C, et al. Echinocandins for the nursery: an update. Curr Drug Metab. 2013;14:203-207.

186. Scott LJ. Micafungin: a review of its use in the prophylaxis and treatment of invasive Candida infections. Drugs. 2012;72:2141-2165.

187. Debnath A, Ndao M, Reed SL. Reprofiled drug targets ancient protozoans: drug discovery for parasitic diarrheal diseases. Gut Microbes. 2013;4:66-71.

188. Rossignol JF, Lopez-Chegne N, Julcamoro LM, et al. Nitazoxanide for the empiric treatment of pediatric infectious diarrhea. Trans $R$ Soc Trop Med Hyg. 2012;106:167-173.
189. Granados CE, Reveiz L, Uribe LG, Criollo CP. Drugs for treating giardiasis. Cochrane Database Syst Rev. 2012;12:CD007787.

190. Tejman-Yarden N, Miyamoto Y, Leitsch D, et al. A reprofiled drug, auranofin, is effective against metronidazole-resistant Giardia lamblia. Antimicrob Agents Chemother. Epub February 12, 2013.

191. Chacín-Bonilla L. Current pharmacotherapy of amebiasis, advances in new drugs, and design of a vaccine. Invest Clin. 2012;53: 301-314.

192. Prichard RK, Basáñez MG, Boatin BA, et al. A research agenda for helminth diseases of humans: intervention for control and elimination. PLoS Negl Trop Dis. 2012;6:e1549.

193. Speich B, Ame SM, Ali SM, et al. Efficacy and safety of nitazoxanide, albendazole, and nitazoxanide-albendazole against Trichuris trichiura infection: a randomized controlled trial. PLoS Negl Trop Dis. 2012;6:e1685.
Infection and Drug Resistance

\section{Publish your work in this journal}

Infection and Drug Resistance is an international, peer-reviewed openaccess journal that focuses on the optimal treatment of infection (bacterial, fungal and viral) and the development and institution of preventive strategies to minimize the development and spread of resistance. The journal is specifically concerned with the epidemiology of antibiotic

\section{Dovepress}

resistance and the mechanisms of resistance development and diffusion in both hospitals and the community. The manuscript management system is completely online and includes a very quick and fair peerreview system, which is all easy to use. Visit http://www.dovepress.com/ testimonials.php to read real quotes from published authors. 